Discussion

Papers

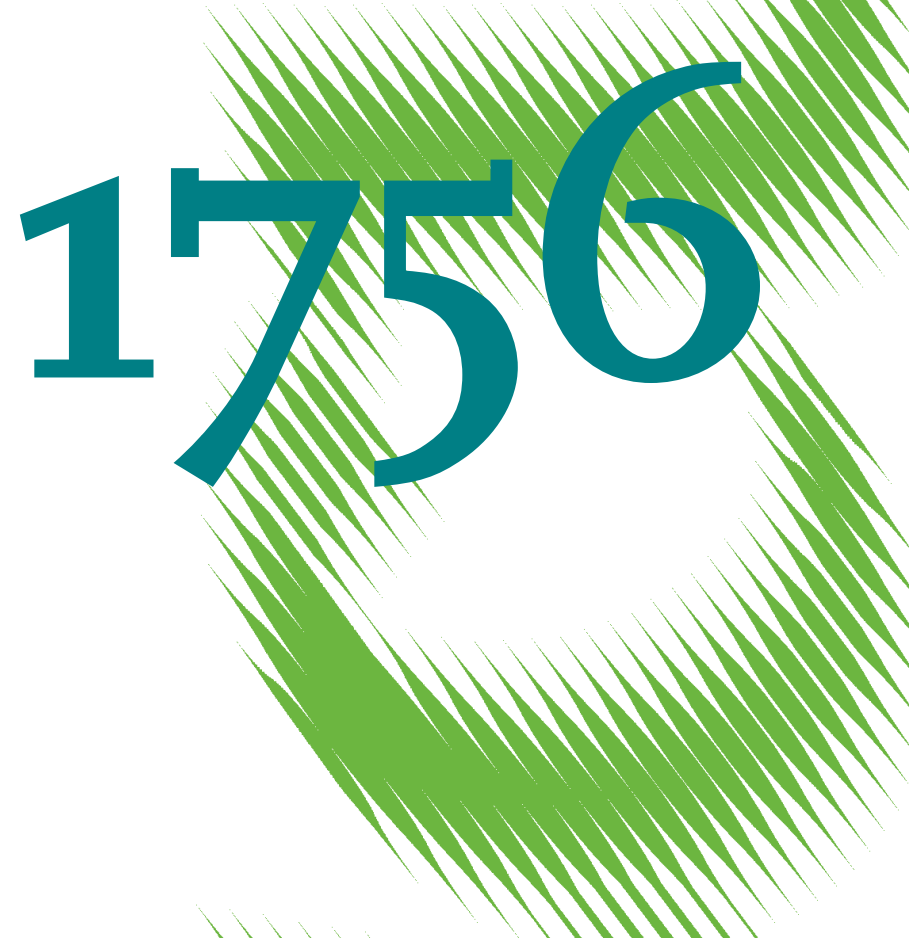

The Entitlement Effect in the Ultimatum Game - Does It Even Exist? 
Opinions expressed in this paper are those of the author(s) and do not necessarily reflect views of the institute.

IMPRESSUM

(C) DIW Berlin, 2018

DIW Berlin

German Institute for Economic Research

Mohrenstr. 58

10117 Berlin

Tel. +49 (30) $89789-0$

Fax +49 (30) $89789-200$

http://www.diw.de

ISSN electronic edition 1619-4535

Papers can be downloaded free of charge from the DIW Berlin website:

http://www.diw.de/discussionpapers

Discussion Papers of DIW Berlin are indexed in RePEc and SSRN:

http://ideas.repec.org/s/diw/diwwpp.html

http://www.ssrn.com/link/DIW-Berlin-German-Inst-Econ-Res.html 


\title{
The Entitlement Effect in the Ultimatum Game - Does it Even Exist?
}

\author{
Elif E. Demiral ${ }^{*}$ \\ Johanna Mollerstrom $^{\dagger}$
}

September 2018

Corrected version of DP 1708

\begin{abstract}
:
Since the seminal paper of Hoffman et al. (1994), an entitlement effect is believed to exist in the Ultimatum Game, in the sense that proposers who have earned their role (as opposed to having it randomly allocated) offer a smaller share of the pie to their matched responder. The entitlement effect is at the core of experimental Public Choice - not just because it concerns the topics of bargaining and negotiations, but also because it relates to the question about under which circumstances actors behave more rational. We conduct three experiments, two in the laboratory and one online, with more than 1,250 participants. Our original motivation was to study gender differences, but ultimately we could not replicate the entitlement effect in the Ultimatum Game in any of our three experiments. Potential reasons for why the replication attempts fail are discussed.
\end{abstract}

Keywords: Ultimatum Game, Public Choice, Experiment, Entitlement, Negotiations, Bargaining, Replications, Gender

Jel Classification: C7, C9, D72, J16

\footnotetext{
* Interdisciplinary Center for Economic Science, George Mason University, 4400 University Dr, Fairfax, VA 22030, USA. E-mail: edemiral@gmu.edu.

${ }^{\dagger}$ Humboldt University, DIW Berlin, and Research Institute for Industrial Economics (IFN), Mohrenstr. 58, 10115 Berlin, Germany. E-mail: johanna.mollerstrom@gmail.com.

We thank Anna Dreber, Dan Houser, Cesar Martinelli, Kevin McCabe, Maria Recalde, the participants in the workshop on Public Choice Experiments at Universite Catholique de Lille 2017, and the participants in the Experimental Gender Economics session at the 2018 ASSA meetings for fruitful interactions about this work. We are grateful to excellent comments on previous versions of the manuscript from Coren Apicella, Puja Bhattacharya, Katie B. Coffman, Christine Exley, Elizabeth Hoffman and Manja Gärtner. Two anonymous referees and the editor for this special issue, Greg DeAngelo, provided extraordinary feedback and support. Finally, we gratefully acknowledge funding for the experiments from the Interdisciplinary Center for Economic Science at George Mason University and from the German Institute for Economic Research (DIW Berlin).
} 


\section{Introduction}

The Ultimatum Game (UG) was studied experimentally for the first time by Güth et al. in 1982. It mimics a simple bargaining situation between two people: The proposer suggests a split of an endowment between herself and the responder. The responder, in turn, decides whether or not to accept the proposal. If she accepts, the endowment is split according to the proposer's suggestion, but if she rejects the offer, both the proposer and the responder leave emptyhanded. The entitlement effect in the UG refers to a situation where proposers who earn their position in the game (as opposed to getting it by chance) offer a smaller share of the endowment to the responder.

This effect was first studied by Hoffman, McCabe, Shachat, and Smith (1994, hereafter HMSS; see also Hoffman and Spitzer, 1985, which partly foreruns the work in HMSS) in a widely cited paper. In their control treatment (which we will call the Random treatment) participants were allocated the roles of proposer and responder by chance. In another treatment, participants took part in a real effort task (a quiz about current events) before playing the UG. Those with above median performance in the task earned the right to be proposers, whereas the rest were given the responder role (we will refer to this treatment as the Entitlement treatment). HMSS document that, in their experiment, the proposers offer less to the responders when they have earned their role as opposed to having it randomly allocated; i.e. they find evidence of an entitlement effect.

The entitlement effect is at the core of experimental Public Choice for at least two reasons. First, bargaining and negotiations is a prominent topic in Public Choice, and this is what the UG captures. ${ }^{1}$ In the world of politics, it is vital to understand how feelings of

\footnotetext{
${ }^{1}$ In fact, the UG is closely related to the legislative bargaining model suggested by Baron and Ferejohn (1989). The prominence of bargaining and negotiations in Public Choice is illustrated in most Public
} 
entitlement affect, for example, an individual's strategies and behavior in legislative bargaining. ${ }^{2}$ In other parts of society, there is also an abundance of instances where people negotiate and bargain: plea bargains, wage negotiations, as well as the daily buying and selling of goods and services are just a few examples.

Second, Public Choice builds on models in which rational individuals seek to advance their own interests (c.f. Mueller, 1997; Farber and Joseph O’Connell, 2010). This means that actors are assumed to behave rationally in the neoclassical sense when making decisions, for example by maximizing own monetary payoffs. Of course, from that perspective, it is intriguing that proposers in the UG generally offer substantial amounts to the responders (rather than the very minimal amount that is the subgame perfect equilibrium). Likewise, respondents often reject offers that are larger than zero - something that they, if they were to adhere to the equilibrium predictions, also would not do (see Güth and Tietz, 1990; Roth, 1995; and Güth and Kocher, 2014 for overviews of experimental UG research and results). Hence it is not surprising that significant effort was invested, especially in the earlier days of experimental economics, into understanding under which circumstances people behave more in accordance with the theoretical predictions. The entitlement effect was put forward as one such prominent example: In HMSS the behavior of entitled proposers is closer to how neoclassical theory predicts that a rational agent should act.

Choice handbooks, see e.g. Mueller (1997), and Farber and Joseph O’Connell (2010). Schram (2008) and Palfrey (2016) both provide excellent overviews of the growing interest in experimental methods within the field of Public Choice.

2 See also and Gailmard (2006), and Cunningham et al. (2017) for examples of Public Choice papers that consider the importance of entitlement in different types of bargaining situations. 
Our work presented here began with an intention to understand gender differences in the entitlement effect (this cannot be investigated using the original HMSS data as information about participants' gender were not collected). Many laboratory and field experiments document that women are less willing to enter negotiations and that they bargain less aggressively than men when actively negotiating (e.g. Stevens et al., 1993; Kaman and Hartel, 1994; Babcock and Laschever, 2003; Babcock et al., 2003; Jeydel and Taylor, 2003; Dittrich et al., 2014; Leibbrant and List, 2014, see also Small et al., 2007; Rigdon, 2012; Exley et al., 2017; Hernandez-Arenaz and Iriberri, 2016, 2018 for additional perspectives on this). One possible reason suggested for this gender gap in negotiations is that women may take less credit for success (c.f. Deaux and Farris, 1977; Apicella et al., 2018) and feel less entitled to higher pay than men (Major et al., 1984; Barron, 2003; for a review, see Gelfand and Stayn, 2012). If this is the case, one way to encourage tougher negotiation behavior by women could be to strengthen their feelings of entitlement. Our original hypothesis, inspired by the experimental literature's finding that women are sometimes more sensitive to contextual factors and social cues than men (see e.g. Croson and Gneezy, 2009, and Ellingsen et al., 2013 - however, see also Andreoni and Vesterlund, 2001, for contradictory results), was that women would change their bargaining behavior more than men, when their feelings of entitlement change.

However, things took an, at least to us, unexpected turn, as the entitlement effect turned out not to replicate. We ran three experiments - two in the laboratory and one online - with a total of 1,254 participants. The design is very close to the original HMSS-design and all three experiments were successful in the sense that our manipulation checks suggest that the treatment worked as intended: for example, both proposers and responders report 
that the proposer was more deserving of her role in the Entitlement treatment than in the Random Treatment. Despite the experiments being successful in that sense, the actual entitlement effect, i.e. proposers offering less to their matched responders in the Entitlement treatment, fail to replicate. In one of the three experiments we find a marginally significant treatment effect ( $\mathrm{p}=0.091$ with t-test) but even this marginal significance goes away when one outlier is excluded. The treatment effects in the other two experiments vary in sign and are far from statistical significance $(\mathrm{p}=0.718$ and $\mathrm{p}=0.316$ in the second and third experiment, respectively). In the pooled data there is also no trace of a significant entitlement effect and, in magnitude, the difference between offers in the two treatments is very small; less than one percent of the endowment. ${ }^{3}$

As we specifically designed our experiment to investigate gender differences in the entitlement effect, our design is for the most part virtually identical to that of HMSS. We did, however, make one change that can be hypothesized to have caused the replication failure. In the Entitlement treatment in HMSS, participants were ranked by performance and the higher performing half were selected as the proposers whereas the rest were given the responder role. In their Random treatment, subjects did not do the real effort task at all, and it was decided by a coin flip who in a pair would be the proposer and the responder. This implies that there are two differences between the proposers in the Entitlement and the Random treatment in HMSS. There is the intended difference: the proposers in the Entitlement treatment have earned their role whereas those in the Random treatment have not. There is, however, also an unintended difference as proposers in the Entitlement treatment

\footnotetext{
${ }^{3}$ As our original intention was to study gender, it is important to point out that we will also provide the analysis by gender. This can partly be found in Section 3, and partly in the Online Appendix, Table A7.
} 
are better performing in the real effort task by design than proposers in the Random treatment. This second difference is not innocuous, as some research indicate a correlation between higher cognitive ability and more rational behavior in economic games. ${ }^{4}$ The fact that the treatment changes two things, means that it is unclear which of these two differences are behind the entitlement effect found in HMSS.

In our experiments, we modify the selection procedure so that we can truthfully tell the proposers in the Entitlement treatment that they earned their role by performing better than the other person in their pair, while at the same time having proposers selected randomly from the same ability distribution in both the Entitlement and the Random treatment. To understand the extent to which this difference between our selection and that of HMSS is responsible for our failure to replicate their finding, we use our data to simulate what our results would have looked like, had we used the HMSS procedure for selecting proposers. Although the results suggest that the entitlement effect might be marginally easier to reproduce when selection of proposers is done as in HMSS, we are still forced to conclude that it is not a robust phenomenon.

As outlined above, our work is related to several strands of literature. First, generally to topics about negotiation and bargaining in Public Choice. Second, to the experimental Public Choice research that aims at understanding under what circumstances people's behavior is more rational in the neoclassical sense. It also, thirdly, is related to the literature attempting to understand gender differences in both negotiation and bargaining,

\footnotetext{
${ }^{4}$ Behavior is certainly not found to differ by ability in all games used in experimental economics, but there are many instances when it does. In those cases, higher ability is generally associated with more rational behavior. See e.g. Ben-Ner et al., 2004, Oechssler et al. (2009), Benjamin et al. (2013), and Mollerstrom and Seim (2014). The evidence of the relation between cognitive ability/cognitive constraints and behavior in the UG is mixed, with Brandstatter and Güth (2002) showing no relation and Cappelletti et al. (2011) indicating that cognitive constraints are associated with higher offers.
} 
as well as, fourthly, the literature examining reactions to social cues and contextual factors. However, given that we conduct three experiments seeking, but ultimately failing, to replicate a well-known experimental result, our paper is, fifth, also intimately related to the fast growing literature that considers questions about replicability, and how replication attempts are crucial for building confidence in science (see e.g. Camerer et al., 2016; Butera and List, 2017; Coffman et al., 2017; Camerer et al., forthcoming).

From here, the paper proceeds as follows. We start by describing the design and implementation of our three experiments in Section 2. In Section 3, we conduct the analysis, document our main findings (or rather, the lack thereof) and investigate potential mechanisms. Section 4 concludes.

\section{The Experiments}

We first describe the experimental design for Experiments 1 and 2, which were conducted in the laboratory. We put special emphasis on the instances where our design deviates from HMSS. Experiment 3, which we conducted online, is described thereafter. For all three experiments, the full instructions and questionnaires are available in the Online Appendix.

\subsection{The Laboratory Version}

The experiment consisted of three parts. In the first part, all participants completed an arithmetic task. They had five minutes in which to provide the answers to a series of math tasks that consisted of adding up five two-digit numbers (c.f. Niederle and Vesterlund, 2007). Participants were informed that they would receive $\$ 0.25$ for each correct answer, which they would receive at the end of the experiment, but that prior to the payout, no information 
about their performance would be provided. Subjects never learned the details about others' performance.

Ahead of the second part of the experiment, participants were matched in pairs. Our experiment entailed two treatments. In the Random treatment, one participant in each pair was randomly given the right to be the proposer in the game that followed. In the Entitlement treatment, this right was awarded to the person who performed better in the math task (ties were broken randomly by the computer). In both treatments, participants were informed whether the proposer (neutrally labeled "Player A" and described as the more advantageous position) and responder (labeled "Player B") roles were allocated randomly or based on performance.

In order to ensure that the selected proposers and responders, respectively, were comparable in characteristics between the treatments, pairing was done in the following way. After the first part, subjects were ranked from highest to lowest according to their performance in the math task (ties were resolved randomly by the computer). The subject ranked first was then matched with the subject ranked second, the subject ranked third was matched with the subject ranked fourth, and so on. The subjects were told that they were matched anonymously to another person in the room; we took care to not claim that the match was random.

In the second part of the experiment, participants played a one-shot UG. Each proposer offered a division of a total endowment of $\$ 20$ between themselves and their matched responder. For the responders we used the strategy method and they stated a minimum acceptable division of the pie, i.e. how large their share would have to be for them to accept the offer. They were informed that if their minimum acceptable offer was less than or equal 
to the actual offer made by the matched proposer, the money would be split as proposed and paid out at the end of the experiment. If the minimum acceptable offer exceeded the offer made, the offer would be rejected and both participants in the pair would receive nothing.

The third part of the experiment consisted of a belief elicitation stage. Proposers were asked to predict the minimum acceptable offer that the matched responder had indicated and, similarly, the responders were asked to state their beliefs about the offer that their matched proposer had actually given. Participants were also asked to predict the number of correct math tasks done both by themselves and by the other people taking part in the same session. For all belief elicitations, participants were informed that they would be rewarded based on the accuracy of their estimates and that a more accurate belief would yield a higher payoff (for details, see the instructions in the Online Appendix).

After the experiment had finished, participants were informed about their payoffs. Before the earnings were privately paid out, participants completed a questionnaire collecting demographic information. We also asked unincentivized questions regarding risk preferences, fairness views, and feelings of deservingness.

\subsubsection{Design Deviations Compared to HMSS}

As our initial objective was to test if the results presented in HMSS are driven by women's behavior, it is natural that our design closely reflect theirs. However, we consciously made a few deviations. First, in order to be able to study gender differences we did collect demographic information. Second, while HMSS use a general knowledge quiz in the first part of the experiment, we use a math task. Third, HMSS only implemented the quiz in in their 
Entitlement treatment, but not in their Random treatment. In order to increase comparability between treatments we chose to implement the math task in both treatments.

Fourth, we use the strategy method for the responders in that we ask them to report minimum acceptable offers as opposed to simply asking them to accept or reject the offer actually extended to them. We did this in order to collect richer information on responder behavior and to be able to elicit more precise beliefs from the proposers about the behavior of their matched responders. The fact that we use the strategy method for the responders does not, however, impact the instructions given to the proposers before they make their decision on offers; thus, our design remains completely comparable to that of HMSS regarding proposer behavior.

The final, and most important, difference between our design and HMSS is the aforementioned pairing mechanism. We implemented this in order to ensure that math ability (and characteristics potentially correlated with this) are held as constant as possible between proposers and responders, respectively, in the two treatments. HMSS, on the other hand, also rank their participants according to ability, but give the proposer roles to the 50 percent of participants who performed best. Thereby it is virtually guaranteed that proposers in the Entitlement treatment are significantly more able in the effort task than proposers in the Random treatment (and that responders in the Entitlement treatment are less able than responders in the Random treatment).

\subsubsection{Implementation in the Laboratory}

The instructions were provided immediately ahead of each part, both on participants' screens and read aloud by the experimenter, thus ensuring common knowledge. On two 
occasions, participants took part in a quiz to ensure that they had understood the instructions and procedures. Those (very few) participants who had problems answering the quiz were given a repetition of the instructions by the experimenter. An even number of subjects participated in each of the experimental sessions. No communication was allowed among participants and matching was done anonymously.

As described above, we ran this experiment twice: Experiment 1 was conducted in February 2016 with 128 undergraduate students participating in ten sessions, and Experiment 2 in early April 2018 with 130 undergraduate students participating in ten sessions. Students were only allowed to take part once. On both occasions, the experiment (programmed with z-Tree, Fischbacher, 2007) was conducted at the ICES Laboratory at George Mason University. The treatments were randomly allocated at the session level.

In Experiment 1, participants earned an average of $\$ 18.40$ (including a fixed showup fee) for their participation in a session that lasted approximately 40 minutes. Although we recruited an equal number of men and women to each session, we had 66 women and 62 men participate; this small deviation from 50/50 was the result of a slight gender difference in show-up rates. In Experiment 2, earnings averaged $\$ 19.60$ (including the show-up fee) and sessions again lasted for approximately 40 minutes. In Experiment 2, we also recruited an equal number for men and women to each session, and, in total, we had 65 women and 65 men participating. Additional summary statistics for all experiments are provided in Table A1 in the Online Appendix. 


\subsection{The Online Version}

The online version of the experiment was designed to be as similar as possible to the laboratory version. However, given the different implementation platform, some changes were necessary. The arithmetic task from the laboratory could, for example, not be used given that subjects generally have uncontrolled access to calculators while taking part in an online experiment, so in the first part of the online version, participants completed a captcha style task consisting of counting the zeros in $7 x 7$ tables consisting of zeros and ones (c.f. Apicella et al., 2017). They had 90 seconds to correctly solve as many tables as possible and received $\$ 0.10$ for each correct answer, to be paid out at the end of the experiment.

Just like in the laboratory, we then informed participants that they had been matched to another participant. In the Random treatment, one of the participants in each pair was randomly given the right to be the proposer in the following game. In the Entitlement treatment this right was awarded to the person in the pair who solved the most tables correctly in the first part. In both treatments, participants were informed whether the proposer (“Player A”, again described as the more advantageous position) and responder (labeled “Player B”) roles were allocated randomly or based on performance.

In the second part of the experiment, participants played the one-shot UG. The proposers offered a division of a total endowment of 300 cents (i.e. the endowment was significantly lower than in the laboratory) between themselves and their matched responder. For the responders, we again used the strategy method. 
Just as in the laboratory, we took care to ensure that the selected proposers and responders are also comparable in performance on the task between the treatments. However, we could not match participants in real time. Instead we started by collecting a small sample of participants who were informed that they may be matched to other subjects (and paid accordingly) at a later point. They were then asked to make decisions as both "Player A" and "Player B," being informed that their actions in the appropriate role would be used in the game with other people, if they were to be matched later. Among these subjects, we chose four to be matched with participants in the main data collection, and they were paid based on these interactions. Two were selected from the Entitlement treatment: one with an extraordinarily high score in the table task (this person solved all available 15 tables correctly) and one with an extraordinarily low score (this person solved zero tables correctly). Two people from the Random treatment were randomly selected.

In the main data collection, participants in the Entitlement treatment were randomly matched to either the person with the extraordinarily high or the extraordinarily low performance (thereby, they were, in practice, randomly allocated to win or lose). They were, truthfully, informed that they were matched with an anonymous person. Since it is important to ensure that players know that their matched partner did indeed know whether the proposer was entitled or not, we took care to explicitly state in the instructions that both people in a matched pair had "done the same task" and "played the same game”. ${ }^{5}$ Further, they were truthfully told that the person in their pair who had the best performance in the task had earned the role of "Player A" whereas the other person would be "Player B". In

\footnotetext{
${ }^{5}$ Still the risk of proposers feeling unsure about what responders know can be greater in the online experiment than in the laboratory experiment, where common knowledge was ensured through instructions being read out loud in addition to them being presented on the computer screen.
} 
the Random treatment participants were matched in a pair with one of the two participants that had previously taken part in the Random treatment. They were truthfully told that it would be randomly decided who in the pair was allocated which role in the game.

The third part of the online experiment consisted of the same belief elicitations and questionnaire questions as in the laboratory experiments, with the one difference that in the online experiment the belief questions were not incentivized.

\subsubsection{Implementation Online}

The instructions were provided immediately ahead of each part and, just like in the laboratory, participants twice took part in a quiz to ensure that they had understood the instructions and procedures. Participants could try as many times as they wanted but had to answer the quiz questions correctly before they could proceed (most participants got all questions right on the first try). Subjects were recruited via the online market Amazon Mturk (participants were located in the US and Canada, and had at least a 95 percent approval rate from previously completed HITs on Mturk), and the experiment was programmed with Qualtrics. The treatments were randomly allocated at the individual level (and in the Entitlement treatment it was randomized, at the individual level, if a person would be matched with a participant with an extraordinarily high or low score).

Participants in the main data collection earned an average of $\$ 2.90$ (including a fixed show-up fee) and the experiment took about 10 minutes to complete. Out of the 996 participants, 492 were women and 504 were men. Participants were only allowed to take part once. ${ }^{6}$

\footnotetext{
${ }^{6}$ In the analysis below we report the results from these $\mathrm{N}=996$ participants, meaning that we do not include the participants who took part in the preliminary data collection that was used to select the four people who
} 


\section{Results}

As the main result of the analysis is that the entitlement effect in the UG does not replicate easily, if at all, we find it important to first document that the failure to replicate did not come from the experiment not "working." Therefore, we start by considering manipulation checks. Thereafter, we analyze the main outcome variable, for one experiment at a time and for the pooled data. Given that our original hypothesis concerned gender, we then give an overview of the results split by female and male participants. We conclude by investigating what role, if any, the choice of how to select proposers and responders plays for our failure to replicate the original HMSS result.

\subsection{Manipulation Checks}

We consider three manipulation checks, reported in Table 1. First, we consider how the treatment impacted the proposers' beliefs about their performance relative to that of others. From part A of Table 1, we see that participants selected as proposers in the Entitlement treatment were significantly more likely, in all three experiments, to believe that they scored strictly better than others in the experiment, compared to those selected as proposers in the Random treatment.

Second, we investigate proposers' feelings of deservingness. This was assessed using a question asking proposers to what extent they felt that they deserved being player A

were matched with the participants in the main data collection. The reason that we exclude them is that we (unbeknownst to them) targeted them based on their superior or inferior performance in a similar table task in another experiment conducted two years earlier. Also, unlike the participants in the main experiment, they acted in both the roles of proposers and responders, and they were told that they may be matched to another participant later (the participants in the main data collection knew that they would be matched for sure). Given their small number (nine in total), it is, however, not surprising that no results change in any meaningful way if we do the main analysis for Experiment 3 using the extended sample of $\mathrm{N}=996+9=1005$ participants (this analysis is available from the authors on request). 
in the pair, on a scale from 1 (not deserving at all) to 10 (extremely deserving). In part B of Table 1, we note that proposers in all three experiment found that they were significantly more deserving of their role in the Entitlement treatment than in the Random treatment.

Table 1: Manipulation Checks

\begin{tabular}{lccc} 
& Entitlement & Random & p of diff \\
\hline A. Fraction of proposers believing that they & & & \\
scored strictly better than others in experiment & & & \\
Experiment 1 & $0.88(0.33)$ & $0.61(0.50)$ & 0.015 \\
Experiment 2 & $0.84(0.37)$ & $0.49(0.51)$ & 0.002 \\
Experiment 3 & $0.40(0.49)$ & $0.24(0.43)$ & 0.000 \\
Pooled & $0.50(0.50)$ & $0.30(0.46)$ & 0.000 \\
\hline B. Feelings of deservingness for having the & & & \\
role of proposer in the game (scale 1-10) & & & \\
Experiment 1 & $9.06(1.41)$ & $7.39(2.02)$ & 0.000 \\
Experiment 2 & $8.13(2.11)$ & $6.64(2.70)$ & 0.016 \\
Experiment 3 & $6.84(2.06)$ & $6.42(2.28)$ & 0.031 \\
Pooled & $7.23(2.14)$ & $6.52(2.31)$ & 0.000 \\
\hline C. Proposer view of what constitutes a fair & & & \\
share for responder & & & \\
Experiment 1 & $0.39(0.11)$ & $0.45(0.11)$ & 0.022 \\
Experiment 2 & $0.42(0.10)$ & $0.47(0.07)$ & 0.016 \\
Experiment 3 & $0.46(0.08)$ & $0.47(0.10)$ & 0.477 \\
Pooled & $0.45(0.09)$ & $0.47(0.10)$ & 0.021 \\
\hline Notes: Average by treatment, standard deviations in parentheses. The p-values are for two-sided t- \\
test of treatment difference, assuming unequal variances. & &
\end{tabular}

Third, all participants were asked to report what they believe constitutes a fair division between proposer and responder, taking on the perspective of a disinterested third party. Part $\mathrm{C}$ of Table 2 shows that in Experiments 1 and 2 the proposers reported a significantly higher fair share for the responder in the Random treatment, compared to the Entitlement treatment. This difference was, however, not significant in Experiment 3. 
Taken together, we conclude that the experiment worked as intended, as proposers' beliefs about their relative performance, their feelings of deserving to be the proposer, and (in two out of three experiments) their "objective" sense of what the fair share for the responder would be, were impacted by the treatment. The corresponding analysis for responders reveals that they were generally affected similarly: they partly believed themselves to be less likely to have scored better than others (but the treatment impact on these beliefs were much weaker for responders than for proposers), they also deemed the proposer as being more deserving of her role, and stated that the fair share for the responder is lower, in the Entitlement treatment compared to the Random treatment. This analysis is reported in Table A2 in the Online Appendix.

\subsection{Main Outcome Variables}

Figure 1 displays the behavior of the participants chosen as the proposers in the three experiments, split by treatment. HMSS find that proposers, when earning their position, offered significantly less to their matched responders than proposers who had been randomly allocated the role. Figure 1 and part A of Table 2 show that, for two of our three experiments, we replicate this in the point estimate. However, the treatment difference is never statistically significant (despite being marginally significant in Experiment 1).

HMSS find no difference between the Entitlement and the Random treatment in responders' rejection rate. Since we ask responders to state a minimum acceptable offer, we have more detailed data on their behavior. We also find no treatment differences in rejection rates and, as depicted in part B of Table 2, we find no treatment difference in minimum acceptable offers that are anywhere close to statistically significant. The point 
estimates vary in sign between the experiments: in Experiment 1 and 2 responders state

Figure 1: Proposer Behavior, by Experiment and Treatment

A. Experiment 1, Entitlement ( $N=33)$

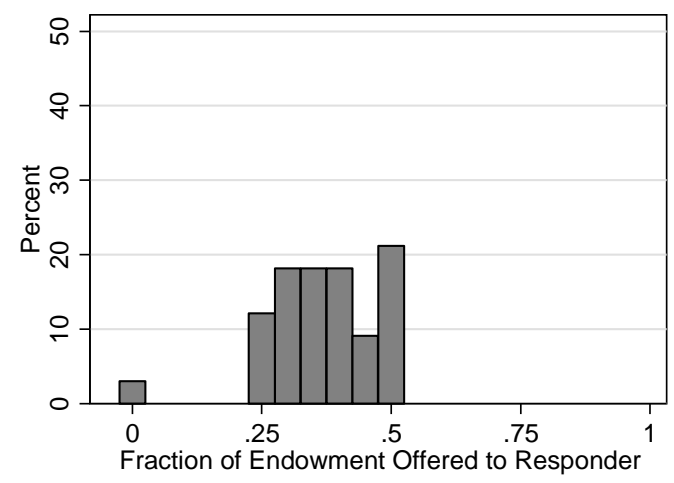

C. Experiment 2, Entitlement $(\mathrm{N}=32)$

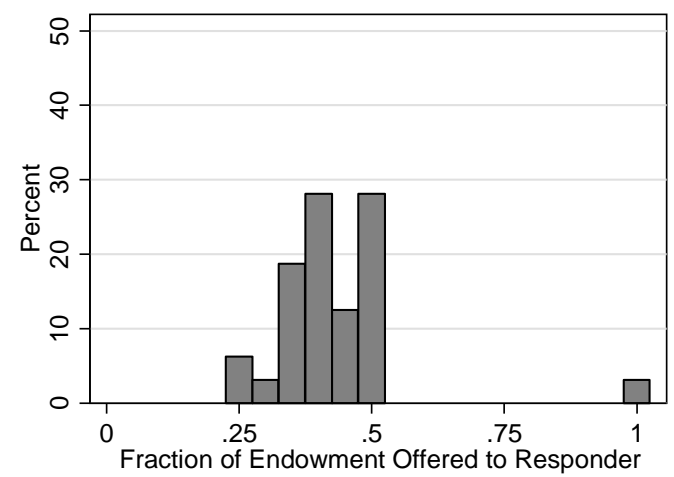

E. Experiment 3, Entitlement $(N=231)$
B. Experiment 1, Random $(N=31)$

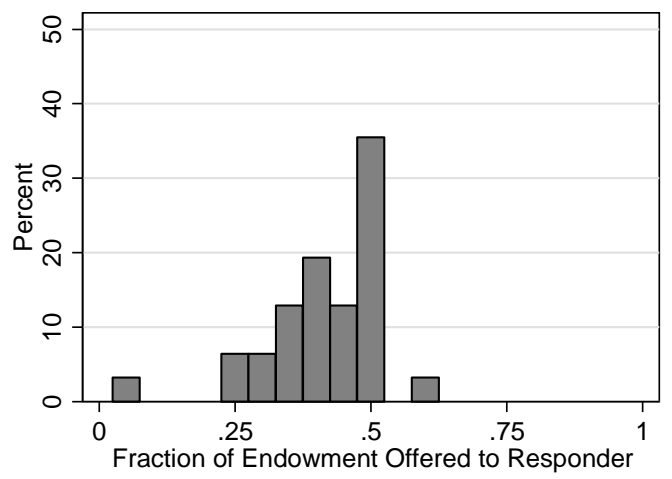

D. Experiment 2, Random ( $N=33)$

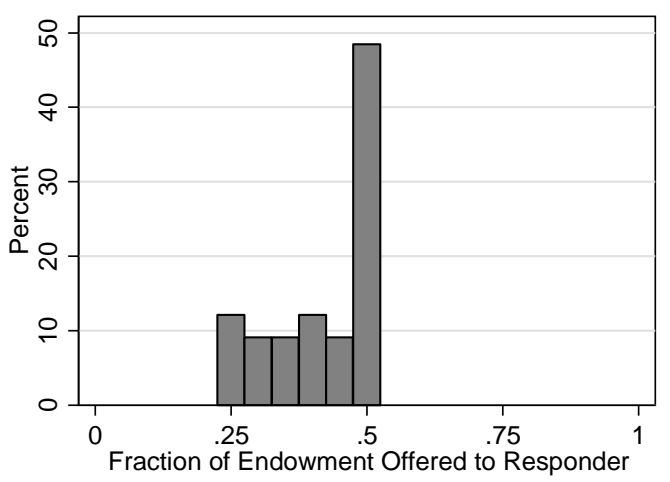

F. Experiment 3, Random $(N=256)$ 

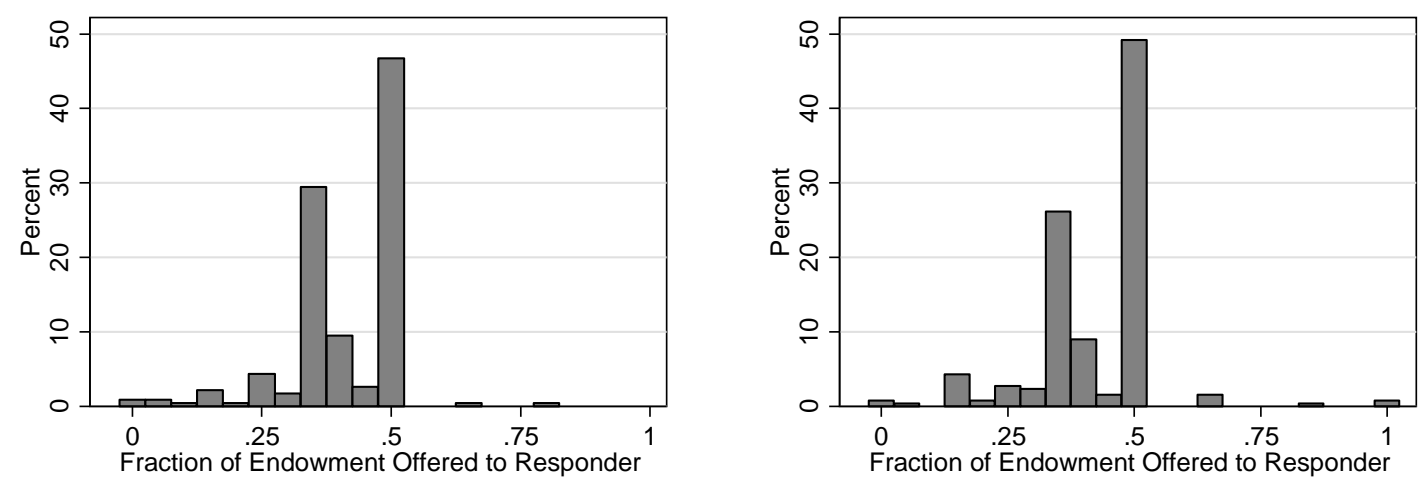

Notes: Histogram of choices by Experiment and Treatment. Width of bars 0.05 .

slightly higher minimum acceptable offers in the Entitlement treatment than in the Random treatment, whereas it is the other way around in Experiment 3.

Table 2: Outcome Variables

\begin{tabular}{llll} 
& Entitlement & Random & $\boldsymbol{p}$ of diff \\
\hline $\begin{array}{l}\text { A. Proposer's offer to responder (fraction } \\
\text { of endowment) }\end{array}$ & & \\
Experiment 1 & $0.37(0.11)$ & $0.41(0.11)$ & 0.091 \\
Experiment 2 & $0.43(0.13)$ & $0.42(0.09)$ & 0.718 \\
Experiment 3 & $0.41(0.11)$ & $0.42(0.13)$ & 0.316 \\
Pooled & $0.41(0.11)$ & $0.42(0.12)$ & 0.182 \\
\hline B. Responders minimum acceptable offer & & & \\
(fraction of endowment) & & \\
Experiment 1 & $0.25(0.12)$ & $0.24(0.15)$ & 0.717 \\
Experiment 2 & $0.28(0.13)$ & $0.25(0.14)$ & 0.438 \\
Experiment 3 & $0.28(0.16)$ & $0.29(0.16)$ & 0.442 \\
Pooled & $0.28(0.15)$ & $0.28(0.15)$ & 0.706 \\
\hline
\end{tabular}

Notes: Average by treatment, standard deviations in parentheses. The p-values are for twosided t-test of treatment difference, assuming unequal variances.

Thus, despite our total sample being about ten times larger than that of HMSS and despite our manipulation checks outlined in Table 1 ensuring us that the experiment worked 
as intended, we fail to replicate the entitlement effect in the UG for proposers and we also find no significant treatment difference for responders.

In the Online Appendix (Tables A3 and A4) we report the results of several robustness checks. We show that replacing the t-test with a Wilcoxon-Mann-Whitney test, or including controls for risk aversion and/or task 1 score, do not change any of the conclusions from Table 2. Our results also hold if outliers are excluded. The Online Appendix also contains an analysis of the belief data, i.e. the data on what proposers in the respective treatments believe about their matched responders' minimum acceptable offer and what responders believe about proposers' offers (Table A5). Just as for actual behavior, there are no statistically significant treatment effects, neither in the individual experiments nor in the pooled data. In addition, the direction of the point estimates for both proposers' and responders' beliefs vary across the three experiments. In addition, we also consider an alternative outcome variable in the Online Appendix (the share of proposer's that offer exactly 50 percent of the endowment to the proposer) and show that there are no treatment effects also when we use this outcome variable (Table A6).

Finally, it is important to note that the behavior of our participants are in other ways similar to what is generally found in the UG literature. For example, Oosterbeek et al. (2004) provides a meta-analysis of UG experiments, reporting that proposers in previous experiments on average offer 40 percent of the endowment to the responder (see also Güth and Kocher, 2014). This matches our results almost exactly. Our finding regarding minimum acceptable offers is also in line with what is documented in the literature. The responders in our experiments state very similar minimum acceptable offers as other studies 
find (see e.g. Thaler, 1988 who reports that in three different experiments, the mean minimum acceptable offer varied between 20 and 26 percent of the endowment. Solnick, 2001, reports that responders on average state a minimum acceptable offer of 31 percent). Overall, we can hence conclude that our results are comparable to previous standard UG results, despite the fact that we do not replicate the entitlement effect.

\subsection{Gender}

Since our original motivation for conducting this experiment was to investigate if the entitlement effect is driven by women, we also conduct our analysis splitting the sample by gender. The result of this analysis can be found in Table 3.

With the exception of the first experiment, results split by gender do not indicate any gender differences. In the first experiment, which is the only experiment where we get anywhere close to replicating the entitlement effect, we find support for our original hypothesis: women offer significantly less in the Entitlement treatment than in the Random treatment whereas men do not. However, there is no trace of this finding in experiments 2 or 3 , nor if the data is pooled.

This also implies that we in almost all cases replicate the finding from Eckel and Grossman (2001), and Solnick (2001), who find no gender difference in proposers’ behavior in the UG. This is true in all three experiments (and in the pooled data), regardless if we analyze the Entitlement and the Random treatment separately or jointly, with one exception: in the Random treatment in Experiment 3, women offer significantly less to their matched responder than men. This analysis is available in table A7 of the Online Appendix. 
Table 3: Outcome Variables by Gender

WOMEN

Entitlement Random $p$ of diff

A. Proposer's offer to responder (fraction of endowment)

Experiment 1

$0.33(0.12) \quad 0.42(0.07) \quad 0.016$

Experiment 2

$0.41(0.08) \quad 0.42(0.10) \quad 0.774$

Experiment 3

$0.42(0.10) \quad 0.42(0.10) \quad 0.668$

Pooled

$0.41(0.10) \quad 0.42(0.10) \quad 0.215$

B. Responders minimum acceptable offer

(fraction of endowment)

Experiment 1

$0.24(0.12) \quad 0.25(0.14) \quad 0.762$

Experiment 2

$0.30(0.12) \quad 0.24(0.10) \quad 0.100$

Experiment 3

$0.28(0.15) \quad 0.27(0.15) \quad 0.603$

Pooled

$0.28(0.14) \quad 0.26(0.14)$

0.473

\section{MEN}

C. Proposer's offer to responder (fraction

of endowment)

Experiment 1

$0.40(0.09) \quad 0.41(0.14) \quad 0.823$

Experiment 2

$0.45(0.16) \quad 0.42(0.09) \quad 0.524$

Experiment 3

$0.41(0.12) \quad 0.42(0.15) \quad 0.334$

Pooled

$\begin{array}{lll}0.41(0.12) & 0.42(0.14) & 0.459\end{array}$

D. Responders minimum acceptable offer

(fraction of endowment)

Experiment 1

$0.28(0.13) \quad 0.23(0.17) \quad 0.364$

Experiment 2

$0.25(0.14) \quad 0.26(0.18) \quad 0.829$

Experiment 3

$0.28(0.16) \quad 0.31(0.16) \quad 0.126$

Pooled

$0.28(0.16) \quad 0.30(0.16) \quad 0.266$

Notes: Average by experiment, treatment, and gender, standard deviations in parentheses. The $\mathrm{p}$-values are for two-sided t-test of treatment differences, assuming unequal variances.

We do find some significant gender difference however: specifically, we replicate two well-studied phenomena that are documented in the literature. As shown in Table 4, women generally report a lower willingness to take risk than men, and women are less 
confident in the sense that they are less likely than men to believe that they scored strictly better than other people participating in the experiment. ${ }^{7}$

\section{Table 4: Gender Differences in Risk Aversion and Confidence}

\begin{tabular}{lccc} 
& Women & Men & $\boldsymbol{p}$ of diff \\
\cline { 2 - 4 } A. Willingness to take risk (scale 1-10) & & & \\
Experiment 1 & $6.12(2.08)$ & $6.85(2.51)$ & 0.075 \\
Experiment 2 & $5.61(2.28)$ & $6.92(2.35)$ & 0.002 \\
Experiment 3 & $5.02(2.62)$ & $6.31(2.45)$ & 0.002 \\
Pooled & $5.20(2.55)$ & $6.43(2.45)$ & 0.000 \\
\hline
\end{tabular}

B. Fraction of participants believing that they scored strictly better than others

Experiment 1

$0.44(0.50) \quad 0.68(0.47) \quad 0.006$

Experiment 2

$0.43(0.50) \quad 0.63(0.49) \quad 0.022$

Experiment 3

$0.21(0.41) \quad 0.30(0.46) \quad 0.001$

Pooled

$0.26(0.44) \quad 0.37(0.48) \quad 0.000$

Notes: Average by gender, standard deviations in parentheses. The $p$-values is for twosided t-test of gender differences, assuming unequal variances. Data on proposers and responders.

\subsection{The Role of Selection}

As discussed in Section 2.1.1, the most notable difference between our design and that of HMSS is that we attempt to hold ability in the part 1 task constant between proposers in the Entitlement and the Random treatment (and between responders in the two treatments). In our data, we also observe that there are no statistically significant differences in task performance, neither between proposers in the two treatments (t-test of difference in score between proposers in the Earnings and the Control treatment respectively, $\mathrm{p}=0.498$,

\footnotetext{
${ }^{7}$ See e.g. Eckel and Grossman, 2002, Moore and Healy, 2008, Croson and Gneezy, 2009, and Charness and Gneezy, 2012. See also Niederle, 2017 for an overview of these, and other, gender differences studied in experimental economics.
} 
$\mathrm{p}=0.223, \mathrm{p}=0.427$, and $\mathrm{p}=0.177$ in Experiment $1,2,3$ and the pooled data respectively) nor between responders $(\mathrm{p}=0.912, \mathrm{p}=0.955, \mathrm{p}=.274, \mathrm{p}=0.320){ }^{8}$

A bivariate regression with offers (as fraction of total endowment) from the proposers regressed on their score from part 1 reveals a negative relation in all three experiments (since we use different tasks in the laboratory and the online version of the experiment, the scores are standardized to take on mean 0 and $\mathrm{SD}=1$ in each respective experiment). However, this association is not statistically significant (the p-value for the coefficient on score is $\mathrm{p}=0.188, \mathrm{p}=0.798, \mathrm{p}=0.218$ and $\mathrm{p}=0.109$ in Experiment $1,2,3$ and the pooled data respectively). The relation is illustrated, for the pooled data, in Figure 2.

Figure 2: Relation between Offers and Standardized Part 1 Score

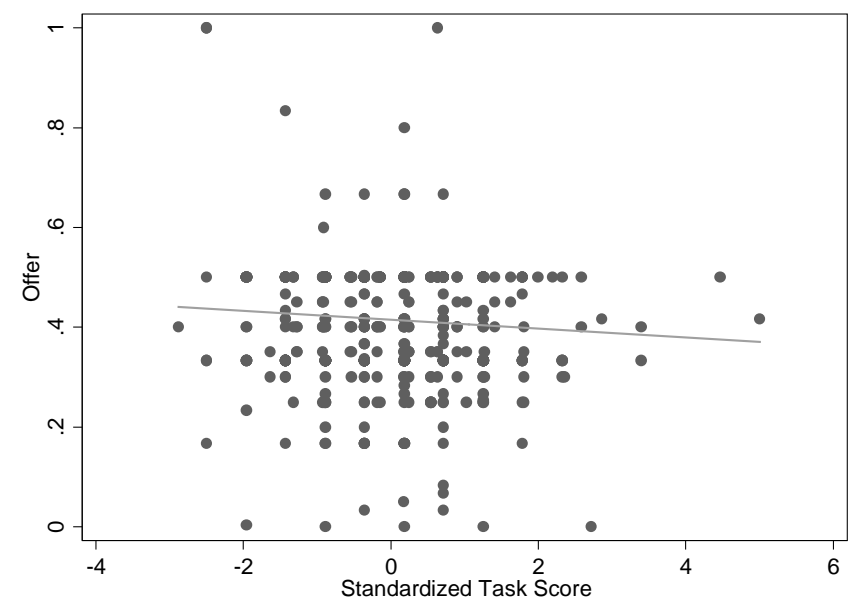

Notes: Scatter plot of offer as fraction of endowment and score in task 1 (standardized to take mean zero and standard deviation one in each respective experiment), including a fitted line.

\footnotetext{
${ }^{8}$ See also Table A1 in the Online Appendix.
} 
The fact that there is a negative (albeit extremely weak - the coefficient on standardized test score is merely -0.0088) relation between a proposer's score and her offer underlines the importance of proper selection of proposers and responders. The reason is that such a negative relation inherently makes the entitlement effect easier to replicate with the HMSS-selection than with ours. ${ }^{9}$

To more fully investigate if our controlling for selection by ability is behind our failure to replicate the HMSS result, we do not need to collect new data. Instead, we use the data from our three experiments to simulate what would have happened if we would have employed the same selection of proposers as HMSS. In this simulation, we rank all participants (for one experiment at a time) in the Entitlement treatment by their score in Part 1. We then find the median score for each experiment and split the group of participants who actually acted as proposers in the Entitlement treatment into two halves: Those with an above median score who would have also been proposers under HMSS selection, and those with a below median score who would not have been proposers. As there are many participants who perform at the median level in the part 1-task, there will be some of those in both groups. In the simulation, it was decided randomly who was selected into the “would have been proposers” group. In order to illustrate as clearly as possible what our results could have been, had we used the HMSS selection, we ran the simulation 1,000 times.

\footnotetext{
${ }^{9}$ There seems to be no relation between responders' score and their minimum acceptable offers - a regression of minimum acceptable offer on score results in a coefficient on score that varies in sign between the experiment (positive in Experiment 1 and 2, negative in Experiment 3) and is far from statistically significant $(\mathrm{p}=0.731, \mathrm{p}=0.692$, and $\mathrm{p}=0.369$, respectively).
} 
We then compare behavior of this simulated group of "would have been" proposers in the Entitlement treatment, with the behavior of the participants actually acting as proposers in the Random treatment. The results are reported in Table 6. We see that the chances of replicating the HMSS result are very slim also when using their method of selecting proposers; only in the case of the offers in the Entitlement treatment being at their very lowest (the min case) do we get anywhere near a statistically significant entitlement effect. ${ }^{10}$

Table 5: Proposer Behavior in Simulated Experiments with HMSS Selection

\begin{tabular}{|c|c|c|c|c|c|c|c|}
\hline & \multicolumn{3}{|c|}{ Entitlement } & \multirow[t]{2}{*}{ Random } & \multicolumn{3}{|c|}{$p$ of diff } \\
\hline & $\min$ & & $\max$ & & $\min$ & median & $\max$ \\
\hline Experiment 1 & $0.37(0.14)$ & $0.37(0.14)$ & $0.37(0.14)$ & $0.41(0.11)$ & 0.244 & 0.244 & 0.244 \\
\hline Experiment 2 & $0.41(0.17)$ & $0.42(0.17)$ & $0.43(0.17)$ & $0.42(0.09)$ & 0.850 & 0.957 & 0.880 \\
\hline Experiment 3 & $0.40(0.11)$ & $0.41(0.12)$ & $0.42(0.11)$ & $0.42(0.13)$ & 0.084 & 0.374 & 0.842 \\
\hline Pooled & $0.40(0.12)$ & $0.41(0.13)$ & $0.41(0.12)$ & $0.42(0.12)$ & 0.058 & 0.238 & 0.590 \\
\hline
\end{tabular}

Notes: Average offer as fraction of endowment. Results for the Entitlement treatment are the minimum, median and maximum result from our simulations. The results for the Random treatment are the same as in Table 2 and are reproduced here for ease of comparison. The $p$-values are for a two-sided t-test of treatment difference (assuming unequal variance) between the respective average offer from the simulated version of the Entitlement treatment and the average offer from the Random treatment. Standard deviations in parentheses.

\section{Concluding Remarks}

To assume that a previously documented result will replicate and plan a related study (such as, in this case, investigate a gender difference) is something most experimental economists have done. Often, it is unproblematic and the replications work. Sometimes, however, it turns out that replication is not possible.

\footnotetext{
${ }^{10}$ In Experiment 1 there were no ties in the selection of proposers in the simulated version of the experiment, which is the reason that the min, median and max are identical. In Online Appendix Table A8, we report the results of a similar counter-factual analysis for responders' behavior. The conclusion is clear: regardless if selection is done in our way, or in the HMSS way, there is no difference between responders' behavior between treatments.
} 
Given that we completely fail to replicate the entitlement effect of the UG, one question is why we thought it was a robust finding before we started. Has it been widely replicated by others? It turns out that it has not. Many authors have built on the work in HMSS, but upon closer inspection, it turns out that there is only one paper (Fleiß, 2015) that studies (and replicates) the entitlement effect in the UG with a design identical to HMSS. ${ }^{11}$ What is, however, widely replicated is the entitlement effect in the Dictator Game (DG), which HMSS also document. ${ }^{12}$ Yet other papers have implemented a related, but distinctively different, design where proposers and responders do not compete to earn their position but instead their endowments. This literature finds that the relative earnings from the initial task serve as a benchmark for what is a fair division of the pie (for an example, see Barber IV and English, 2018, and the references therein). ${ }^{13}$

We want to make clear that we, of course, cannot claim to have shown that the entitlement effect in the UG, as documented by HMSS, can never replicate. It may be, for example, that the reason that we do not replicate it is that we use a math task instead of a current events quiz in the first part of the experiment, and one could ask if whereas current

\footnotetext{
${ }^{11}$ In their meta-analysis of UG experiments, Güth and Kocher (2014) cite only one paper as a related study to HMSS, a remotely related paper which studies the entitlement effect on free-form bargaining over infeasible claims (Gächter and Riedl, 2005).

${ }^{12}$ As this is not the focus of our experiment, we did not discuss the DG part of HMSS above. Here the authors document an entitlement effect in the DG, i.e. that dictators who earn their position give less than dictators who were randomly allocated their role. This finding has been widely replicated, see e.g. Cherry, 2001, Cherry et al., 2002; Oxoby and Spraggon, 2008; Schurter and Wilson, 2009; Banerjee and Chakravarty, 2014; Korenok et al., 2017. Also, in his meta-analysis of DG experiments, Engel (2011) reports that the entitlement effect in the DG is substantial and significant in situations where dictators earn their positions or the endowment. However, the selection problem, with dictators in the Entitlement treatment being from a different part of the ability distribution than the dictators in the Random treatment, remains both in HMSS and in later work. In future work, we plan to investigate if the entitlement effect in the DG holds under the selection mechanism used here. Given that we find a significant treatment difference in what proposers state as their view of what the fair share for the responder is, and that it is easier for them to directly implement this in a DG than in an UG, it may be that the entitlement effect in the DG is robust to proper selection, but this remains to be tested.

${ }^{13}$ To our knowledge, none of the experiments using this design controls for selection by ability, however.
} 
event quizzes simply is the one task that evoke strong feelings of entitlement, maybe the math task is not? We simply report what we did and what the result was: Using a very similar design to that of HMSS in order to conduct three experiments - both in the laboratory and online - with more than 1,250 participants, we failed to replicate the entitlement effect in the UG. Also, it is worth noting that our manipulation checks strongly suggest that feelings of entitlement were affected as intended, but that behavior in the UG nevertheless did not change between treatments.

Despite the fact that our main finding is a null, there are at least two important lessons to be learned. First, we now know that earning an advantageous bargaining position does not necessarily make one behave as a tougher negotiator or a more rational decision maker. Second, and maybe more importantly, our findings confirm the importance of replication attempts, whether in science in general or in economics specifically. 


\section{References:}

Andreoni, James, Lise Vesterlund. "Which is the Fair Sex? Gender Differences in Altruism.” Quarterly Journal of Economics, 116, no. 1 (2001): 293-312.

Apicella, Coren L., Elif E. Demiral and Johanna Mollerstrom. "No Gender Difference in Willingness to Compete when Competing against Self.” American Economic Review, Papers and Proceedings, 107, no. 5 (2017): 136-140.

Apicella, Coren L., Elif E. Demiral, and Johanna Mollerstrom. ”Gender Differences in Self- and Other-competition.” (2018). Mimeo.

Babcock, Linda and Sara Laschever. Women Don't Ask: Negotiation and the Gender Divide. Princeton: Princeton University Press, 2003.

Babcock, Linda, Sara Laschever, Michele Gelfand, and Deborah Small. "Nice Girls Don’t Ask.” Harvard Business Review, 81, no. 10 (2003).

Banerjee, Priyodorshi, and Sujoy Chakravarty. "Psychological ownership, group affiliation and other-regarding behaviour: Some evidence from dictator games.” Global Economics and Management Review 19, no. 1 (2014): 3-15.

Barber IV, Benjamin, and William English. "The Origin of Wealth Matters: Merit, Fairness, and Equality in the Ultimatum Game.” (2018). Mimeo. 
Baron, David P., and John A. Ferejohn. "Bargaining in legislatures.” American Political Science Review 83, no. 4 (1989): 1181-1206.

Barron, Lisa A. “Ask and You Shall Receive? Gender Differences in Negotiators’ Beliefs about Requests for a Higher Salary.” Human Relations 56, no. 6 (2003): 635-662.

Benjamin, Daniel J., Sebastian A. Brown, and Jesse M. Shapiro. “Who is 'Behavioral’? Cognitive Ability and Anomalous Preferences.” Journal of the European Economic Association, 11, no. 6 (2013): 1231-1255.

Ben-Ner, Avner, Fanmin Kong, and Louis Putterman. ”Share and share alike? Genderpairing, personality, and cognitive ability as determinants of giving.” Journal of Economic Psychology, 25 (2004): 581-589.

Brandstatter, Hermann and Werner Güth. "Personality in dictator and ultimatum games.” Central European Journal of Operations Research, 10, no. 3 (2002): 191-216.

Butera, Luigi and John List. “An Economic Approach to Alleviate the Crisis of Confidence in Science: With an Application to the Public Goods Game”. Artefactual Field Experiments, 00608 (2017). 
Camerer, Colin F., Anna Dreber, and Magnus Johannesson. "Replication and other Practices for Improving Scientific Quality in Experimental Economics.” In Handbook of Research Methods and Applications and Experimental Economics (Arthur Schram and Aljaž Ule, editors) (forthcoming)

Camerer, Colin F., Anna Dreber, Eskil Forsell, Teck-Hua Ho, Jürgen Huber, Magnus Johannesson, Michael Kirchler, Johan Almenberg, Adam Altmejd, Taizan Chan, Emma Heikensten, Felix Holzmeister, Taisuke Imai, Siri Isaksson, Gideon Nave, Thomas Pfeiffer, Michael Razen \& Hang Wu. "Evaluating Replicability of Laboratory Experiments in Economics.” Science, 315 (2016): 1433-1436.

Cappelletti, Dominique, Werner Güth, and Matteo Ploner. "Being of two minds: Ultimatum offers under cognitive constraints.” Journal of Economic Psychology, 32 (2011): 940950.

Charness, Gary, and Uri Gneezy. "Strong Evidence for Gender Differences in Risk Taking.” Journal of Economic Behavior \& Organization, 83, no. 1 (2012): 50-58.

Cherry, Todd L. "Mental accounting and other-regarding behavior: Evidence from the lab.” Journal of Economic Psychology 22, no. 5 (2001): 605-615.

Cherry, Todd L., Peter Frykblom, and Jason F. Shogren. "Hardnose the dictator." The American Economic Review 92, no. 4 (2002): 1218-1221. 
Coffman, Lucas, Rania Gihleb, Douglas Hanley and Alistair Wilson. “Assessing the Rate of Replications in Economics.” American Economic Review (P\&P), 107, no. 5 (2017): 2731.

Croson, Rachel, and Uri Gneezy. "Gender Differences in Preferences." Journal of Economic Literature 47, no. 2 (2009): 448-474.

Croson, Rachel, and Uri Gneezy. Gender Differences in Preferences. Journal of Economic Literature, 47, no. 2 (2009): 448-474.

Cunningham, Scott., Greg DeAngelo, and John Tripp “Craigslist’s Effect on Violence Against Women.” (2017) Mimeo.

Deaux, Kay, and Elizabeth Farris. “Attributing Causes for One’s Own Performance: The Effects of Sex, Norms, and Outcome.” Journal of Research in Personality 11, no. 1 (1977): $59-72$.

Diermeier, Daniel, and Sean Gailmard. "Self-interest, inequality, and entitlement in majoritarian decision-making." Quarterly Journal of Political Science 1, no. 4 (2006): 327350. 
Dittrich, Marcus, Andreas Knabe, and Kristina Leipold. “Gender Differences In Experimental Wage Negotiations.” Economic Inquiry 52, no 2 (2014): 862-873.

Eckel, Catherine C., and Philip Grossman. "Sex Differences and Statistical Stereotyping in Attitudes Toward Financial Risk.” Evolution and Human Behavior, 23, no. 4 (2002): 281295.

Eckel, Catherine C., and Philip J. Grossman. "Chivalry and Solidarity in Ultimatum Games.” Economic Inquiry 39, no. 2 (2001): 171-188.

Ellingsen, Tore, Magnus Johannesson, Johanna Mollerstrom, and Sara Munkhammar. "Gender Differences in Social Framing Effects.” Economics Letters 118, no. 3 (2013): 470-472.

Engel, Christoph. "Dictator games: A meta study." Experimental Economics 14, no. 4 (2011): 583-610.

Exley, Christine L., Muriel Niederle, and Lise Vesterlund. Knowing When to Ask: The Cost of Leaning In. (2017). National Bureau of Economic Research Working Paper, No. w22961.

Farber, Daniel A., and Anne Joseph O'Connell (editors). Research Handbook on Public Choice and Public Law. Edward Elgar Publishing Ltd., Cheltenham, UK (2010) 
Fischbacher, Urs. “Z-Tree: Zurich Toolbox for Ready-Made Economic Experiments.” Experimental Economics 10, no. 2 (2007): 171-178.

Fleiß, Jürgen. "Merit norms in the ultimatum game: an experimental study of the effect of merit on individual behavior and aggregate outcomes.” Central European Journal of Operations Research 23, no. 2 (2015): 389-406.

Gächter, Simon, and Arno Riedl. “Moral property rights in bargaining with infeasible claims.” Management Science 51, no. 2 (2005): 249-263.

Gelfand, Michele, and Heidi Stayn. "Gender differences in the propensity to initiate negotiations." In Social Psychology and Economics. Edited by David De Cremer, Marcel Zeelenberg, J. Keith Murnighan, New York: Psychology Press, 239-263, 2012.

Güth, Werner, and Martin Kocher. "More than thirty years of ultimatum bargaining experiments: Motives, variations, and a survey of the recent literature”. Journal of Economic Behavior and Organization, 108 (2014): 396-409.

Güth, Werner, and Reinhard Tietz. "Ultimatum Bargaining Behavior - A survey and comparison of experimental results.” Journal of Economic Psychology, 11 (1990): 414449. 
Güth, Werner, Rolf Schmittberger, and Bernd Schwarze. An Experimental Analysis of Ultimatum Bargaining. Journal of Economic Behavior and Organization, 3 (1982): 367-388.

Hernandez-Arenaz, Iñigo and Nagore Iriberri. Gender Differences in Alternating-Offer Bargaining: An Experimental Study. CEPR Discussion Paper No. DP12561 (2018).

Hernandez-Arenaz, Iñigo and Nagore Iriberri. Women Ask for Less (Only from Men): Evidence from Alternating-Offer Bargaining in the Field. CEPR Discussion Paper No. DP11514 (2016).

Hoffman, Elizabeth and Matthew Spitzer. "Entitlements, rights, and fairness: An experimental examination of subjects' concepts of distributive justice.” Journal of Legal Studies, 14, no. 2 (1985): 259-297.

Hoffman, Elizabeth, Kevin McCabe, Keith Shachat, and Vernon Smith. "Preferences, Property Rights, and Anonymity in Bargaining Games.” Games and Economic Behavior 7, no. 3 (1994): 346-380.

Jeydel, Alana, and Andrew J. Taylor. "Are women legislators less effective? Evidence from the US House in the 103rd-105th Congress." Political Research Quarterly 56, no. 1 (2003): 19-27. 
Kaman, Vicki S., and Charmine E.J. Hartel. "Gender Differences in Anticipated Pay Negotiation Strategies and Outcomes.” Journal of Business and Psychology 9, no. 2 (1994): 183-197.

Korenok, Oleg, Edward Millner, and Laura Razzolini. "Feelings of ownership in dictator games.” Journal of Economic Psychology 61 (2017): 145-151.

Leibbrandt, Andreas, and John A. List. "Do Women Avoid Salary Negotiations? Evidence from a Large-Scale Natural Field Experiment.” Management Science 61, no. 9 (2014): 2016-2024.

Major, Brenda, Dean B. McFarlin, and Diana Gagnon. “Overworked and Underpaid: On the Nature of Gender Differences in Personal Entitlement.” Journal of Personality and Social Psychology 47, no. 6 (1984): 1399-1412.

Mollerstrom, Johanna, and David Seim. "Cognitive Ability and the Demand for Redistribution.” PLOS ONE, 9(10): 109955.

Moore, Don A., and Paul J. Healy. "The Trouble with Overconfidence.” Psychological Review 115, no. 2 (2008): 502-517.

Mueller, Dennis (editor). Perspectives on Public Choice: A Handbook. Cambridge University Press, Cambridge, UK, 1997 
Niederle, Muriel, and Lise Vesterlund. "Do Women Shy Away From Competition? Do Men Compete Too Much?” The Quarterly Journal of Economics 122, no. 3 (2007): 10671101.

Niederle, Muriel. Gender. In Handbook of Experimental Economics, Vol. 2 (John H. Kagel and Alvin E. Roth, editors). Princeton University Press, Princeton, New Jersey, 2017.

Oechssler, Jörg, Andreas Roider and Patrick W. Schmitz. “Cognitive abilities and behavioral biases.” Journal of Economic Behavior and Organization, 72 (2009): 147-152.

Oosterbeek, Hessel, Randolph Sloof, and Gijs Van De Kuilen. “Cultural differences in ultimatum game experiments: Evidence from a meta-analysis.” Experimental Economics 7, no. 2 (2004): 171-188.

Oxoby, Robert J., and John Spraggon. "Mine and yours: Property rights in dictator games." Journal of Economic Behavior \& Organization 65, no. 3 (2008): 703-713.

Palfrey, Thomas R. "Experiments in political economy." The Handbook of Experimental Economics 2 (2016): 347-434. 
Rigdon, Mary. “An Experimental Investigation of Gender Differences in Wage Negotiations.” (2012). Working Paper.

Roth, Alvin E. Bargaining Experiments. In Handbook of Experimental Economics (John H. Kagel and Alvin E. Roth, editors). Princeton University Press, Princeton, New Jersey, 1995.

Schram, Arthur J.H.C. Experimental Public Choice. In: Readings in Public Choice and Constitutional Political Economy (Charles K. Rowley and Friedrich G. Schneider, editors) Springer, Boston, MA, 2008

Schurter, Karl, and Bart J. Wilson. "Justice and fairness in the dictator game.” Southern Economic Journal 76, no. 1 (2009): 130-145.

Small, Deborah A., Michele Gelfand, Linda Babcock, and Hilary Gettman. "Who Goes to the Bargaining Table? The Influence of Gender and Framing on the Initiation of Negotiation.” Journal of Personality and Social Psychology 93, no. 4 (2007): 600-613.

Solnick, Sara. "Gender Differences in the Ultimatum Game.” Economic Inquiry 39, no. 2 (2001): 189-200. 
Stevens, Cynthia K., Anna G. Bavetta, and Marilyn E. Gist. “Gender Differences in the Acquisition of Salary Negotiation Skills: The Role of Goals, Self-Efficacy, and Perceived Control.” The Journal of Applied Psychology 78, no. 5 (1993): 723-735.

Thaler, Richard H. “Anomalies: The ultimatum game.” Journal of Economic Perspectives 2, no. 4 (1988): 195-206. 


\section{Online Appendix}

\section{Appendix A: Additional Analysis}

Table A1: Summary Statistics by Experiment, Treatment and Gender

\begin{tabular}{|c|c|c|c|c|c|}
\hline & & \multicolumn{2}{|c|}{ Random } & \multicolumn{2}{|c|}{ Entitlement } \\
\hline & & Women & Men & Women & Men \\
\hline \multirow{5}{*}{ Experiment 1} & $\mathrm{~N}$ & $N=30$ & $N=32$ & $N=36$ & $N=30$ \\
\hline & No. of proposers & $\mathrm{N}=16$ & $\mathrm{~N}=15$ & $\mathrm{~N}=14$ & $\mathrm{~N}=19$ \\
\hline & No. of responders & $\mathrm{N}=14$ & $\mathrm{~N}=17$ & $N=22$ & $\mathrm{~N}=11$ \\
\hline & Age & $20.00(1.66)$ & $20.50(1.80)$ & $21.11(2.61)$ & $20.40(1.67)$ \\
\hline & Task Score & $7.73(2.56)$ & $7.13(3.03)$ & $8.08(2.81)$ & $7.03(2.51)$ \\
\hline \multirow{5}{*}{ Experiment 2} & $\mathrm{~N}$ & $\mathrm{~N}=33$ & $\mathrm{~N}=33$ & $\mathrm{~N}=32$ & $\mathrm{~N}=32$ \\
\hline & No. of proposers & $N=16$ & $\mathrm{~N}=17$ & $\mathrm{~N}=16$ & $N=16$ \\
\hline & No. of responders & $\mathrm{N}=17$ & $\mathrm{~N}=16$ & $\mathrm{~N}=16$ & $\mathrm{~N}=16$ \\
\hline & Age & $20.24(1.84)$ & $20.00(1.31)$ & $20.84(1.51)$ & $20.65(2.10)$ \\
\hline & Task Score & $7.91(2.67)$ & $6.42(2.42)$ & $7.78(2.28)$ & $7.41(2.69)$ \\
\hline \multirow{5}{*}{ Experiment 3} & $\mathrm{~N}$ & $N=253$ & $\mathrm{~N}=255$ & $N=239$ & $N=249$ \\
\hline & No. of proposers & $N=129$ & $N=127$ & $N=117$ & $N=114$ \\
\hline & No. of responders & $N=124$ & $N=128$ & $\mathrm{~N}=122$ & $N=135$ \\
\hline & Age & $38.86(11.55)$ & 35.70 (10.7) & $38.86(11.55)$ & 36.45 (11.38) \\
\hline & Task Score & $4.83(1.70)$ & $4.51(2.05)$ & 4.69 (1.79) & $4.61(1.90)$ \\
\hline
\end{tabular}

Notes: Standard deviations in parentheses. Age in years. Task score is the score in the first part of the experiment (not standardized). 
Table A2: Manipulation Checks for Responders

\begin{tabular}{llll} 
& Entitlement & Random & p of diff \\
\hline A. Fraction of responders believing that they & & & \\
scored strictly better than others in experiment & & & \\
Experiment 1 & $0.24(0.46)$ & $0.48(0.51)$ & 0.046 \\
Experiment 2 & $0.38(0.49)$ & $0.42(0.51)$ & 0.691 \\
Experiment 3 & $0.18(0.39)$ & $0.22(0.42)$ & 0.271 \\
Pooled & $0.21(0.41)$ & $0.27(0.44)$ & 0.071 \\
\hline B. Feelings of deservingness for the matched & & & \\
person having the role of proposer (scale 1-10) & & \\
Experiment 1 & $7.45(2.40)$ & $6.06(3.20)$ & 0.055 \\
Experiment 2 & $8.00(2.06)$ & $7.27(2.17)$ & 0.171 \\
Experiment 3 & $6.90(2.32)$ & $5.84(1.79)$ & 0.000 \\
Pooled & $7.07(2.33)$ & $6.01(2.05)$ & 0.000 \\
\hline C. Responder view of what constitutes a fair & & & \\
share for responder & & & \\
Experiment 1 & $0.40(0.11)$ & $0.48(0.05)$ & 0.012 \\
Experiment 2 & $0.45(0.07)$ & $0.49(0.04)$ & 0.019 \\
Experiment 3 & $0.48(0.06)$ & $0.50(0.06)$ & 0.012 \\
Pooled & $0.47(0.10)$ & $0.49(0.06)$ & 0.000 \\
\hline Notes: Average by treatment, standard deviations in parentheses. The p-values are for two-sided t- \\
test of treatment difference, assuming unequal variances. & &
\end{tabular}

Table A3: Robustness Checks 1, Different Tests

\begin{tabular}{|c|c|c|c|c|c|c|}
\hline & Entitlement & Random & $\begin{array}{c}p, \text { t-test, no } \\
\text { controls }\end{array}$ & $\begin{array}{c}p, \text { WMW } \\
\text { test }\end{array}$ & $\begin{array}{c}p, \text { Wald-test, } \\
\text { controlling for } \\
\text { score }\end{array}$ & $\begin{array}{l}p, \text { Wald-test, } \\
\text { controlling for score } \\
\text { and risk aversion }\end{array}$ \\
\hline \multicolumn{7}{|c|}{ A. Proposer's offer to responder (fraction } \\
\hline \multicolumn{7}{|c|}{ of endowment) } \\
\hline Experiment 1 & $0.37(0.11)$ & $0.41(0.11)$ & 0.091 & 0.050 & 0.110 & 0.155 \\
\hline Experiment 2 & $0.43(0.13)$ & $0.42(0.09)$ & 0.718 & 0.591 & 0.681 & 0.655 \\
\hline Experiment 3 & $0.41(0.11)$ & $0.42(0.13)$ & 0.316 & 0.761 & 0.335 & 0.341 \\
\hline Pooled & $0.41(0.11)$ & $0.42(0.12)$ & 0.182 & 0.158 & 0.207 & 0.241 \\
\hline \multicolumn{7}{|c|}{ B. Responders minimum acceptable offer } \\
\hline \multicolumn{7}{|c|}{ (fraction of endowment) } \\
\hline Experiment 1 & $0.25(0.12)$ & $0.24(0.15)$ & 0.717 & 0.722 & 0.715 & 0.720 \\
\hline Experiment 2 & $0.28(0.13)$ & $0.25(0.14)$ & 0.438 & 0.499 & 0.442 & 0.468 \\
\hline Experiment 3 & $0.28(0.16)$ & $0.29(0.16)$ & 0.442 & 0.570 & 0.415 & 0.416 \\
\hline Pooled & $0.28(0.15)$ & $0.28(0.15)$ & 0.706 & 0.777 & 0.690 & 0.689 \\
\hline
\end{tabular}


Table A4: Robustness Checks 2, Excluding Outliers

\begin{tabular}{|c|c|c|c|c|}
\hline REMOVING SOME OUTLIERS & Entitlement & Random & $p$ of diff & Number of obs excluded \\
\hline \multirow{2}{*}{\multicolumn{5}{|c|}{$\begin{array}{l}\text { A. Proposer's offer to responder (fraction } \\
\text { of endowment) }\end{array}$}} \\
\hline & \multicolumn{4}{|c|}{ of endowment) } \\
\hline Experiment 1 & $0.37(0.11)$ & $0.41(0.10)$ & 0.138 & 1 \\
\hline Experiment 2 & $0.41(0.07)$ & $0.42(0.09)$ & 0.694 & 1 \\
\hline Experiment 3 & $0.41(0.11)$ & $0.41(0.11)$ & 0.734 & 11 \\
\hline Pooled & $0.40(0.10)$ & $0.41(0.11)$ & 0.346 & 13 \\
\hline \multirow{2}{*}{\multicolumn{5}{|c|}{$\begin{array}{l}\text { B. Responders minimum acceptable offer } \\
\text { (fraction of endowment) }\end{array}$}} \\
\hline & & & & \\
\hline Experiment 1 & $0.25(0.12)$ & $0.24(0.15)$ & 0.717 & 0 \\
\hline Experiment 2 & $0.28(0.13)$ & $0.25(0.14)$ & 0.438 & 0 \\
\hline Experiment 3 & $0.28(0.16)$ & $0.29(0.15)$ & 0.561 & 1 \\
\hline Pooled & $0.28(0.15)$ & $0.28(0.15)$ & 0.848 & 1 \\
\hline \multicolumn{5}{|c|}{ REMOVING ALL OUTLIERS } \\
\hline \multicolumn{5}{|c|}{$\overline{C . \text { Proposer's offer to responder (fraction }}$} \\
\hline \multicolumn{5}{|c|}{ of endowment) } \\
\hline Experiment 1 & $0.38(0.09)$ & $0.41(0.10)$ & 0.244 & 2 \\
\hline Experiment 2 & $0.41(0.07)$ & $0.42(0.09)$ & 0.694 & 1 \\
\hline Experiment 3 & $0.41(0.10)$ & $0.41(0.10)$ & 0.882 & 14 \\
\hline Pooled & $0.41(0.10)$ & $0.41(0.10)$ & 0.523 & 17 \\
\hline \multicolumn{5}{|c|}{ D. Responders minimum acceptable offer } \\
\hline \multicolumn{5}{|c|}{ (fraction of endowment) } \\
\hline Experiment 1 & $0.28(0.10)$ & $0.24(0.14)$ & 0.700 & 3 \\
\hline Experiment 2 & $0.30(0.10)$ & $0.27(0.12)$ & 0.309 & 3 \\
\hline Experiment 3 & $0.28(0.15)$ & $0.29(0.14)$ & 0.445 & 2 \\
\hline Pooled & $0.28(0.15)$ & $0.29(0.14)$ & 0.709 & 8 \\
\hline
\end{tabular}

Notes: Average by experiment, and treatment, standard deviations in parentheses. Removing some outliers means excluding proposers who offer more than 50 percent, and responders who set there minimal acceptable offer over 50 percent. Removing all outliers means that, in addition, proposers offering zero are excluded, as are responders who report a minimum acceptal offer of zero. The $p$-values are for two-sided t-test of treatment differences, assuming unequal variances. 
Table A5: Beliefs

\begin{tabular}{llcc} 
& Entitlement & Random & $\boldsymbol{p}$ of diff \\
\hline $\begin{array}{l}\text { A. Proposer's beliefs about responder's minimum } \\
\text { acceptable offer (fraction of endowment) }\end{array}$ & & & \\
Experiment 1 & $0.24(0.09)$ & $0.26(0.07)$ & 0.210 \\
Experiment 2 & $0.28(0.09)$ & $0.29(0.11)$ & 0.794 \\
Experiment 3 & $0.30(0.11)$ & $0.28(0.12)$ & 0.066 \\
Pooled & $0.29(0.11)$ & $0.28(0.11)$ & 0.210 \\
\hline B. Responder's belief about proposers offer & & & \\
(fraction of endowment) & & & \\
Experiment 1 & $0.34(0.11)$ & $0.38(0.13)$ & 0.161 \\
Experiment 2 & $0.38(0.11)$ & $0.37(0.11)$ & 0.713 \\
Experiment 3 & $0.37(0.16)$ & $0.37(0.15)$ & 0.854 \\
Pooled & $0.36(0.15)$ & $0.37(0.15)$ & 0.652 \\
\hline
\end{tabular}

Notes: Average by treatment, standard deviations in parentheses. The $p$-values are for two-sided ttest of treatment differences, assuming unequal variances.

Table A6: Alternative Outcome Variable

\begin{tabular}{lccc} 
& Entitlement & Random & $\boldsymbol{p}$ of diff \\
\hline $\begin{array}{l}\text { Share of proposers offering exactly } 50 \text { percent } \\
\text { of the endowment to the responder }\end{array}$ & & \\
Experiment 1 & $0.21(0.42)$ & $0.35(0.49)$ & 0.231 \\
Experiment 2 & $0.28(0.47)$ & $0.48(0.51)$ & 0.094 \\
Experiment 3 & $0.46(0.50)$ & $0.49(0.50)$ & 0.581 \\
Pooled & $0.42(0.49)$ & $0.48(0.50)$ & 0.138 \\
\hline Notes: Average by treatment, standard deviations in parentheses. The $p$-values are for two-sided t- \\
test of treatment difference, assuming unequal variances.
\end{tabular}




\section{Table A7: Gender Differences in the UG}

\begin{tabular}{|c|c|c|c|c|c|c|}
\hline & \multicolumn{3}{|c|}{ Entitlement } & \multicolumn{3}{|c|}{ Random } \\
\hline & Women & Men & $p$ of diff & Women & Men & $p$ of diff \\
\hline \multicolumn{7}{|c|}{ A. Proposer's offer to responder } \\
\hline \multicolumn{7}{|c|}{ (fraction of endowment) } \\
\hline Experiment 1 & $0.33(0.12)$ & $0.40(0.09)$ & 0.079 & $0.42(0.07)$ & $0.41(0.14)$ & 0.708 \\
\hline Experiment 2 & $0.41(0.08)$ & $0.45(0.16)$ & 0.412 & $0.42(0.10)$ & $0.42(0.09)$ & 0.969 \\
\hline Experiment 3 & $0.42(0.10)$ & $0.41(0.12)$ & 0.492 & $0.42(0.10)$ & $0.42(0.15)$ & 0.922 \\
\hline Pooled & $0.41(0.10)$ & $0.41(0.12)$ & 0.862 & $0.42(0.10)$ & $0.42(0.14)$ & 0.980 \\
\hline \multicolumn{7}{|c|}{ B. Responders minimum acceptable } \\
\hline \multicolumn{7}{|c|}{ offer (fraction of endowment) } \\
\hline Experiment 1 & $0.24(0.12)$ & $0.28(0.13)$ & 0.334 & $0.25(0.14)$ & $0.23(0.17)$ & 0.712 \\
\hline Experiment 2 & $0.30(0.12)$ & $0.25(0.14)$ & 0.289 & $0.24(0.10)$ & $0.26(0.18)$ & 0.597 \\
\hline Experiment 3 & $0.28(0.15)$ & $0.28(0.16)$ & 0.887 & $0.27(0.15)$ & $0.31(0.16)$ & 0.026 \\
\hline Pooled & $0.28(0.14)$ & $0.28(0.16)$ & 0.841 & $0.26(0.14)$ & $0.30(0.16)$ & 0.043 \\
\hline
\end{tabular}

Notes: Average by gender, standard deviations in parentheses. The $\mathrm{p}$-values are for two-sided t-test of gender difference, assuming unequal variances.

\section{Table A8: Responder Behavior in Simulated Experiment with HMSS Selection}

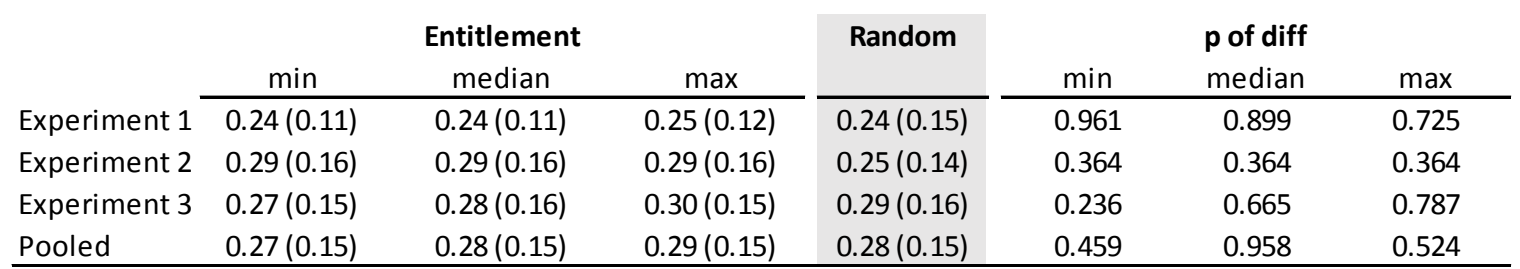

Notes: Minimum acceptabel offer as fraction of endowment. Results for the Entitlement treatment are the minimum, median and maximum result from our simulations. The results for the Random treatment are the same as in Table 2 and are reproduced here for ease of comparison. The $p$-values are for two-sided t-test of treatment difference (assuming unequal variance) between the respective average offer from the simulated version of the Entitlement treatment and the average offer from the Random treatment. Standard deviations in parentheses. 


\section{Appendix B: Instructions in the Laboratory}

Welcome to the experiment. The experiment is now beginning. Please silence and put away your electronic devices. No communication is allowed during this experiment. If you have questions at any point in this experiment, please raise your hand and an experimenter will come by and answer your question privately.

Please answer the questions on this screen:

Are you a student?

Have you ever participated an ICES experiment before?

Please indicate your gender?

What is your age?

This is an experiment about decision making. You have already earned $\$ 5$ for showing up on time. You may earn more depending on your decision and the decisions made by the other participants. You will be paid privately in cash when the experiment is over. The experiment is conducted anonymously and decisions you make will never be linked to your identity. There are several parts in the experiment and instructions will be given at the beginning of each part.

We will go through the instructions for part 1 now, so please follow.

\section{Part 1 - Math Task}

Random Treatment: We now begin with the first part of the experiment where you can earn money. In this part of the experiment you are asked to solve as many math problems as you can. You have five minutes available. In each problem, you will sum up five two-digit numbers. An example is: $27+18+89+50+17$. In this case the correct answer is 201. For each correct answer, you will receive $\$ 0.25$. At the end of the experiment, you will learn how many of your answers were correct and how much you earned. This will then be paid out in cash together with your other earnings.

In the second part of the experiment, you will be paired with an anonymous person. Each pair will consist of one player A and one player B. Being player A is more advantageous, and on average, player A can earn more money than player B.

Your roles in the second part of the experiment will be determined randomly. The computer will randomly pick player A and B in each pair.

At the end of the experiment, you will learn how many of your answers were correct and how much you earned. This will then be paid out in cash together with your other earnings.

Entitlement treatment: We now begin with the first part of the experiment where you can earn money. In this part of the experiment you are asked to solve as many math problems as you can. You have five minutes available. In each problem, you will sum up five two-digit numbers. An example is: $27+18+89+50+17$. In this case the correct answer is 201. For each correct answer, you will receive $\$ 0.25$. In addition to that, your scores in the math task will determine the roles you will have in the second part of the experiment. 
In the second part of the experiment, you will be paired with an anonymous person. Each pair will consist of one player A and one player B. Being player A is more advantageous, and on average, player A can earn more money than player B.

The number of correct answers you give in the first part will determine your roles in the second part of the experiment. The person who solves most math problems correctly in each pair will earn the right to be player A.

At the end of the experiment, you will learn how many of your answers were correct and how much you earned. This will then be paid out in cash together with your other earnings.

\section{Quiz about part 1}

We will now make sure that everyone has understood the instructions for part 1. Please answer the questions on the screen. If you need help, please raise your hand. When you have finished answering, please press "I understand". If any of your answers are incorrect, the program will tell you so and you get to answer that question again.

1) How much money will you receive for each math problem you solve correctly?

2) If you solve 11 problems, 8 of them correctly, how much money will you receive?

3) If you solve 6 problems, 4 of them correctly, how much money will you receive?

4) If you solve 12 questions, all of them correctly, how much money will you receive?

5) Which player will have an advantageous position in the second part of the experiment?

[Math task is completed]

Random Treatment: It has now been determined how many of your answers were correct. At the end of the experiment, you will learn how many correct answers you gave and the money you earned will be given to you in cash. We now move on to part 2 of the experiment where you can earn more money.

Entitlement Treatment: It has now been determined how many of your answers were correct and who in the pair earned the right to be player A. At the end of the experiment, you will learn how many correct answers you gave and the money you earned will be given to you in cash. We now move on to part 2 of the experiment where you can earn more money.

\section{Part 2-Ultimatum Game}

Random treatment: In this part, you are paired with an anonymous person in this room. You will not be told who that person is either during or after the experiment, and s/he will not be told who you are. Each pair consists of one player A and one player B. We will tell you whether you are player A or player B after we have gone over the instructions. 
Entitlement treatment: In this part, you are paired with an anonymous person in this room. You will not be told who that person is either during or after the experiment, and s/he will not be told who you are. Each pair consists of one player A and one player B. We will tell you whether you have earned the right to be player A or not after we have gone over the instructions.

The experiment is conducted as follows: a sum of $\$ 20$ will be given to player $\mathrm{A}$ in each pair. Player A will then suggest how much of the $\$ 20$ that s/he should keep and how much of the $\$ 20$ should be given to player B. Player B will then decide whether to accept or reject this suggestion. If player $B$ accepts, the $\$ 20$ will be divided as player A suggested. If player $B$ rejects, both players will receive nothing.

Random treatment: Who in the pair ended up being player A or B is randomly determined by the computer. So each person in a pair has an equal chance of being selected as player A or player B.

You will soon learn if you have been picked randomly as player A or not.

Entitlement treatment: Who in the pair ended up being player A or B is determined by your scores from the task you completed in part 1 . The participant who solved more math problems correctly in your pair earned the right to be player A. In case of a tie, the computer randomly selected player A or player B.

You will soon learn if you have earned the right to be player A or not. If you solved more math problems than the other person in your pair, you have earned the right to be player $\mathrm{A}$. If not, you will play the game as player $\mathrm{B}$.

\section{THE GAME}

Once the roles are announced, you will play the game. First, player A will make a suggestion about how to divide the $\$ 20$ between player $\mathrm{A}$ and player $\mathrm{B}$. Then player $\mathrm{B}$ will decide if s/he is accepting or rejecting this suggestion. If player B accepts, player A and player B get the amounts player A suggested. If player B rejects, both players get nothing.

Let's look at two examples:

Random treatment: Example 1: Imagine that you are randomly selected to be player $\mathrm{A}$ and are given $\$ 20$ to divide between yourself and player B. You suggest to give $\$ 6$ to player B. Thus you want to keep $\$ 14$ for yourself $(20-6=14)$. Suppose player B has decided to accept any suggestion that gives her/him more than $\$ 5$. Therefore player B accepts this offer and the $\$ 20$ is split as you suggested. That is, you receive \$14 and player B receives $\$ 6$ from this game.

Entitlement treatment: Example 1: Imagine that you have earned the right to be player A and are given $\$ 20$ to divide between yourself and player B. You suggest to give $\$ 6$ to player B. Thus you want to keep $\$ 14$ for yourself $(20-6=14)$. Suppose player B has decided to accept any suggestions that gives her/him more than $\$ 5$. Therefore player B accepts this offer and the $\$ 20$ is split as you suggested. That is, you receive $\$ 14$ and player $B$ receives $\$ 6$ from this game. 
Example 2: Imagine that you are player B. Your counterpart player A is given $\$ 20$ to divide between himself/herself and you. Player A suggests to give $\$ 5$ to you. Thus s/he wants to keep $\$ 15$ for him/herself (20-5=15). Suppose you have decided that you will accept any suggestion that gives you more than $\$ 7$. Therefore you reject this offer. That is, both of you receive nothing from this game.

\section{Quiz about part 2}

We will now make sure that everyone has understood the instructions for part 2. Please answer the questions on the screen. If you need help, please raise your hand. When you have finished answering, please press "I understand". If any of your answers are incorrect, the program will tell you so and you get to answer that question again.

After everyone has finished answering, we will announce if you are selected as player A in your pair or not.

\section{Random treatment: Quiz question 1)}

There are two people in your pair and 1 person is randomly selected to be player A. What is the chance of you being selected?

Entitlement treatment: Quiz question 1)

If you did not earn the right to be player A, then which player are you going to be?

Random treatment: Quiz question 2)

If you are not randomly selected as player A, then which player are you going to be?

Entitlement treatment: Quiz question 2)

What determines your role in this experiment?

- It is randomly assigned

- It is determined by my math score compared to the other person's score in my pair

Random treatment: Quiz question 3)

Suppose you are randomly selected to be the player A, and you suggest to give $\$ 7$ out of $\$ 20$ to player B. Suppose player B rejects this.

How much does player A receive from this game?

How much does player $\mathrm{B}$ receive from this game?

Entitlement treatment: Quiz question 3)

Suppose you have earned the right to be the player A, and you make an offer of $\$ 7$ out of $\$ 20$ to player B. Suppose player B rejects this.

How much does player A receive from this game?

How much does player B receive from this game?

Random treatment: Quiz question 4)

Suppose the other person in your pair is randomly selected to be player A, and that $\mathrm{s} / \mathrm{he}$ makes you an offer of $\$ 4$. Suppose you accept this. 
How much does player A receive in this game?

How much does player $B$ receive in this game?

Entitlement treatment: Quiz question 4)

Suppose the other person in your pair has earned the right to be player A, and that s/he makes you an offer of $\$ 4$. Suppose you accept this.

How much does player A receive in this game?

How much does player $\mathrm{B}$ receive in this game?

[Announcement of the roles]

Random treatment: On this screen you get to know if you are randomly selected as player A or if you will play the game as player B.

Again, the game is played anonymously. You will never get to learn your counterpart's identity.

As a reminder: First, player A in each pair will make a suggestion to player B on how to split the $\$ 20$. Then, player B will decide to accept or reject this suggestion.

Entitlement treatment: On this screen you get to know if you have earned the role of player A or if you will be player B.

If you solved more math problems than the other person in your pair, you have earned the right to be player A. If not, you will play the game as player B.

Again, the game is played anonymously. You will never get to learn your counterpart's identity.

As a reminder: First, player A in each pair will make a suggestion to player B on how to split the \$20. Then, player B will decide to accept or reject this suggestion.

\section{Ultimatum Game}

For player A:

Random treatment: Congratulations! You were randomly selected as player A. You will now play the game with player B.

Entitlement treatment: Congratulations! You have earned the right to be player A. You will now play the game with player B.

You are now given $\$ 20$. You will make a suggestion on how to divide this $\$ 20$ between yourself and player $\mathrm{B}$.

If player B accepts your suggestion the $\$ 20$ will be split as you suggest. That is player B gets your offer, and you keep \$20 minus the offer.

If player $\mathrm{B}$ rejects, you both get zero.

Please state the dollar amount that you want to offer to player B

Please state the dollar amount that you want to keep for yourself

For player B: 
Random treatment: Unfortunately you were not selected as player A. Hence you are player B. You will now play the game with the other person in your pair who is randomly selected to be player A.

Entitlement treatment: Unfortunately you did not earn the right to be player A. Hence you will play the game as player B. You will now play the game with the other person in your pair who has earned the right to be player $\mathrm{A}$.

Player A is now making a suggestion on how to split the $\$ 20$ between two of you.

Before you see player A's actual offer, for every possible suggestion please choose if you accept this or not.

Your payment from this game is going to be determined by the one suggestion that player A actually makes and your choice on whether to accept or reject this suggestion.

If you accept player A's suggestion, the $\$ 20$ will be split as player A suggested. If you reject, then both of you will receive nothing.

Note that this is your final decision. Whatever split player A suggests, your decision here will be used to either accept or reject it.

[Ultimatum Game is played]

The game has been conducted and you will learn the outcome at the end of the experiment, just before your earnings are paid out in cash. We now proceed to part 3 , which is the last part of the experiment. Part 3 will consist of several screens.

\section{Part 3- Beliefs}

In this part you will state your beliefs and predictions about your experience and the experience of others in the experiment. You will receive $\$ 2$ for each prediction that is exactly correct. If your estimate is off by one, you will receive $\$ 1$. That means it is in your best interest to guess correctly.

Question 1) (A's only)

When player B decided to accept/reject, s/he saw all possible suggestions from you, not only the suggestion you actually made. Which possible suggestions do you think player B accepted and which suggestions s/he rejected?

If you suggested to keep $\$ 20$ and give $\$ 0$ to player B, what do you think s/he chose? If you suggested to keep \$19 and give \$1 to player B, what do you think s/he chose?

$$
\ldots
$$

Question 1) (B's only)

How many dollars do you believe that your counterpart player A suggested that you will get?

How many dollars do you believe that your counterpart player A suggested that s/he will keep? 


\section{Question 2a)}

How many math problems do you think you answered correctly in part 1? (The maximum was 15)

\section{Question 2b)}

How many math problems do you think the people in this room, who participated in the experiment with you, solved correctly on average? (The maximum was 15. Please round up your answer to the closest integer)

\section{Question 3)}

What do you think the gender of the other person in your pair is?

For this question, you will get $\$ 2$ if your answer is exactly correct and \$0 if it is wrong.

[Subjects learn their payoffs]

\section{Questionnaire}

While we prepare your payments, please answer the following questions:

$$
\text { 1) (A’s only) }
$$

On a scale of 1 to 10 , do you feel that you deserved to be player A?

No, I did not deserve it at all

Yes, I definitely deserved it

$$
\text { 2) (B’s only) }
$$

On a scale of 1 to 10, do you feel that the other person in your pair deserved to be player A?

No, s/he did not deserve it at all

Yes, s/he definitely deserved it

3) According to your opinion, what would be a 'fair' distribution of the $\$ 20$ from the perspective of a third party who is not part of the pair?

The fair dollar amount for player A would be:

The fair dollar amount for player B would be:

4) How do you see yourself: Are you generally a person who is fully prepared to take risks or do you try to avoid taking risks?

Not at all willing

Very willing

5) How willing are you to negotiate, in general

Not at all willing

Very willing 
6) Did the random selection of the roles affect how you played in the game in part 2? Yes No

Why or why not?

7) How long ago was your most recent negotiation that you initiated?

8) What did you negotiate about?

9) What is your major?

10) Please specify your ethnicity:

White

Hispanic/Latino

Black/African American

Asian/Pacific Islander

Other

Prefer not to say

11) Was there any part of the experiment that confused you? Please explain.

12) Do you have any other comments? 


\section{Appendix C: Instructions Online}

To receive your bonus payment, you must enter your Mechanical Turk ID into the box below and then click to continue.

Your WorkerID starts with the letter A and is followed by letters or numbers. It is not your email address.

To ensure accuracy, please copy and paste your WorkerID from Mturk. This makes sure that there are no mistakes. An example of a common mistake is that "0" (the number) is written instead of an "O" (the letter). Mistakes like that may significantly delay your bonus payment.

Enter your WorkerID here:

Thank you for participating in our study. We estimate that this study will take about 5-10 minutes to complete. After you have finished, you will receive a completion code. Please return to the HIT on MTurk and enter the completion code in the space provided, in order to receive your credit.

You will receive $\$ 0.50$ for completing the HIT. In addition to that, you can earn a bonus. We expect average bonus payments to be around $\$ 2$. The maximum bonus payment is $\$ 4.50$. The bonus will be paid to you through Amazon Mturk in the next few business days.

We will now go through the instructions. Please read them carefully. You are only eligible for bonus payment if you adhere to the instructions.

As established researchers and long-term Requesters on Amazon MTurk, we promise that the information in this survey is truthful and accurate. We never use deception: the decisions you make are real, any group that you participate in is real and we always send you the money that you earn in your interactions with others in this HIT. If you have any questions about this research, please feel free to email us at survey.research.mturk@gmail.com.

Before we start with the experiment, please answer the following questions:

What is your age (in years)?

Ethnicity:

What is your gender?

What is your country of residence?

Are you currently a student? 
This is an experiment about decision making. The experiment is conducted anonymously and decisions you make will never be linked to your identity. There are several parts in the experiment, and instructions will be given at the beginning of each part.

We will now go through the instructions for part 1.

Entitlement Treatment: In this part, you are asked to solve a series of problems by counting the number of zeros (0) in tables consisting of zeros (0) and ones (1). You will be given 90 seconds to solve as many tables as possible. For each correct answer, you will receive 10 cents.

After the 90 seconds are up you will automatically continue to the next page. That means that you do not need to keep time yourself, but can concentrate on solving the tables. If you solve all available tables before the time is up, please just wait for the survey to continue automatically.

At the end of the experiment, you will learn how many of your answers were correct and how much you earned in this part.

In addition to that, your scores in this task will determine the roles you will have in the second part of the experiment.

In the second part of the experiment, you will be paired with an anonymous person. Each pair will consist of one player A and one player B. Being player A is more advantageous, and on average, player A can earn more money than player B.

The number of correct answers you give in the first part will determine your roles in the second part of the experiment. The person in each pair who solves most tables correctly will earn the right to be player A.

We will now make sure that everyone has understood the instructions for part 1. Please answer the questions below.

Q1 How much money, in cents, will you receive for each table you solve correctly?

Q2 If you solve 6 tables, 4 of them correctly, how much money (in cents) will you receive?

Q3 If you solve 4 tables, 3 of them correctly, how much money (in cents) will you receive?

Q4 If you solve 7 tables, all of them correctly, how much money (in cents) will you receive? 
Q5 Which player will have an advantageous position in the second part of the experiment?

Random Treatment: In this part, you are asked to solve a series of problems by counting the number of zeros ( 0 ) in tables consisting of zeros (0) and ones (1). You will be given 90 seconds to solve as many tables as possible. For each correct answer, you will receive 10 cents.

After the 90 seconds are up you will automatically continue to the next page. That means that you do not need to keep time yourself, but can concentrate on solving the tables. If you solve all available tables before the time is up, please just wait for the survey to continue automatically.

At the end of the experiment, you will learn how many of your answers were correct and how much you earned in this part.

In the second part of the experiment, you will be paired with an anonymous person. Each pair will consist of one player A and one player B. Being player A is more advantageous, and on average, player A can earn more money than player B.

Your roles in the second part of the experiment will be determined randomly. The computer will randomly pick player A and B in each pair.

We will now make sure that everyone has understood the instructions for part 1. Please answer the questions below.

Q1 How much money, in cents, will you receive for each table you solve correctly?

Q2 If you solve 6 tables, 4 of them correctly, how much money (in cents) will you receive?

Q3 If you solve 4 tables, 3 of them correctly, how much money (in cents) will you receive?

Q4 If you solve 7 tables, all of them correctly, how much money (in cents) will you receive?

Q5 Which player will have an advantageous position in the second part of the experiment?

Thank you for answering the quiz! Please click to continue to part 1 . Remember that you have 90 seconds available to solve as many tables as possible.

[Table task is completed] 
Entitlement Treatment: It has now been determined how many of your answers were correct and who in your pair earned the right to be player A. We now move on to part 2 of the experiment where you can earn more money.

Random Treatment: It has now been determined how many of your answers were correct. At the end of the experiment, you will learn how many correct answers you gave. We now move on to part 2 of the experiment where you can earn more money.

Entitlement Treatment: In this part, you will be paired with an anonymous person who is part of the same experiment as you. This other person has done the same task in part 1, and has taken part in the same game as the one that you are about to play. You will not be told who that person is either during or after the experiment, and s/he will not be told who you are. Each pair consists of one player A and one player B.

We will tell you whether you have earned the right to be player A or not after we have gone over the instructions.

The experiment is conducted as follows: a sum of 300 cents is given to player A in each pair. Player A then suggests how much of the 300 cents that s/he should keep and how much of the 300 cents that should be given to player B. Player B will then decide whether to accept or reject this suggestion. If player B accepts, the 300 cents will be divided as player A suggested. If player B rejects, both players will receive nothing from this part of the experiment.

Who in the pair ends up being player A or B is determined by your scores from the task you completed in part 1 . The participant who solved more tables correctly in your pair earns the right to be player $\mathrm{A}$.

Let's look at two examples:

Example 1: Imagine that you have earned the right to be player A and are given 300 cents to divide between yourself and player B. You suggest to give 90 cents to player B. Thus you want to keep 210 cents for yourself $(300-90=210)$. Suppose player B has decided to only accept a suggestion that gives her/him more than 75 cents. Therefore player B accepts this offer and the 300 cents are split as you suggested. That is, you receive 210 cents and player $\mathrm{B}$ receives 90 cents from this game.

Example 2: Imagine that you are player B. Your counterpart player A is given 300 cents to divide between himself/herself and you. Player A suggests to give 75 cents to you. Thus s/he wants to keep 225 cents for him/herself (300-75=225). Suppose you have decided that you will only accept a suggestion that gives you more than 100 cents. Therefore you reject this offer. That is, both of you receive nothing from this game. 
We will now make sure that everyone has understood the instructions for part 2. Please answer the questions on the screen.

When you are done with this quiz, we will announce if you earned the right to be player A in your pair or not.

Q1 What determines your role in this experiment?

Q2 If you did not earn the right to be player A, then which player are you going to be?

Q3 Suppose you have earned the right to be the player A, and you suggest to give 100 cents out of 300 cents to player B. Suppose player B rejects this. How much does player A receive from this game? How much does player $B$ receive from this game?

Q4 Suppose the other person in your pair has earned the right to be player A, and that s/he makes you an offer of 60 cents out of 300 cents. Suppose you accept this. How much does player A receive from this game? How much does player B receive from this game?

Random Treatment: In this part, you will be paired with an anonymous person who is part of the same experiment as you. This person sees the same instructions as you, and has done the same task in part 1. You will not be told who that person is either during or after the experiment, and s/he will not be told who you are. Each pair consists of one player A and one player B.

We will tell you whether you are player A or player B after we have gone over the instructions.

The experiment is conducted as follows: a sum of 300 cents is given to player A in each pair. Player A then suggests how much of the 300 cents that s/he should keep and how much of the 300 cents that should be given to player B. Player B will then decide whether to accept or reject this suggestion. If player B accepts, the 300 cents will be divided as player A suggested. If player B rejects, both players will receive nothing from this part of the experiment.

Who in the pair ended up being player A or B is randomly determined by the computer. So each person in a pair has an equal chance of being selected as player A or player B.

Let's look at two examples:

Example 1: Imagine that you are randomly selected to be player A and are given 300 cents to divide between yourself and player B. You suggest to give 90 cents to player B. Thus you want to keep 210 cents for yourself $(300-90=210)$. Suppose player B has decided to only accept a suggestion that gives her/him more than 75 cents. Therefore player $\mathrm{B}$ accepts this offer and the 300 cents is split as you suggested. That is, you receive 210 cents and player $\mathrm{B}$ receives 90 cents from this game. 
Example 2: Imagine that you are player B. Your counterpart player A is given 300 cents to divide between himself/herself and you. Player A suggests to give 75 cents to you. Thus s/he wants to keep 225 cents for him/herself (300-75=225). Suppose you have decided that you will only accept a suggestion that gives you more than 100 cents. Therefore you reject this offer. That is, both of you receive nothing from this game.

We will now make sure that everyone has understood the instructions for part 2. Please answer the questions on the screen.

When you are done with this quiz, we will announce if you were randomly selected as player A in your pair or not.

Q1 There are two people in your pair and one person is randomly selected to be player A. What is the chance of you being selected?

Q2 If you are not randomly selected as player A, then which player are you going to be?

Q3 Suppose you are randomly selected to be the player A, and you suggest to give 100 cents out of 300 cents to player B. Suppose player B rejects this. How much does player A receive from this game? How much does player $B$ receive from this game?

Q4 Suppose the other person in your pair is randomly selected to be player A, and that s/he makes you an offer of 60 cents out of 300 cents. Suppose you accept this. How much does player A receive from this game? How much does player $\mathrm{B}$ receive from this game?

Entitlement Treatment: You will now get to know if you have earned the right to be player A because you solved more tables than the other person in your pair.

If not, you will play the game as player B.

As a reminder: First, player A in each pair will make a suggestion to player B on how to split the 300 cents. Then, player B will decide to accept or reject this suggestion.

Random Treatment: You will now get to know if you are randomly selected as player A or if you will play the game as player B.

As a reminder: First, player A in each pair will make a suggestion to player B on how to split the 300 cents. Then, player B will decide to accept or reject this suggestion.

Entitlement Treatment, Player A: Congratulations! You have earned the right to be player A. You will now play the game with player B. 
Entitlement Treatment, Player B: Unfortunately you did not earn the right to be player A. Hence you will play the game as player B. You will now play the game with the other person in your pair who earned the right to be player $\mathrm{A}$.

Random Treatment, Player A: Congratulations! You were randomly selected as player A. You will now play the game with player B.

Random Treatment, Player B: Unfortunately you were not selected as player A. Hence you are player B. You will now play the game with the other person in your pair who was randomly selected to be player A.

Player A: Since you are player A, you have been given 300 cents. Please make a suggestion on how to divide these 300 cents between yourself and player B.

If player B accepts your suggestion the 300 cents will be split as you suggest. That means that player B gets the amount that you offer him/her, and you keep the rest.

If player B rejects, you both get zero.

I offer this amount (in cents) to player B:

I want to keep this amount (in cents) for myself:

Player B: Player A has made a suggestion on how to split the 300 cents between the two of you.

Your payment from this game is going to be determined by the suggestion that player $\mathrm{A}$ made and your choice on whether to accept or reject this suggestion.

Please now state what the smallest offer to you is, that you are willing to accept.

If the actual offer from Player $\mathrm{A}$ is larger than, or equal to, this amount then you accept the offer and the 300 cents will be split as Player A suggests.

If the actual offer from Player A is smaller than this amount, then you reject the offer and both of you receive nothing.

Note that this is your final decision. Whatever split player A suggests, your decision here will be used to either accept or reject it.

The smallest offer to me that I am willing to accept is (in cents):

Player A: The game has now been conducted and you will learn the outcome after you have answered the questions on this screen. 
Q1 When player B decided to accept or reject your offer, s/he stated the smallest amount that s/he would be willing to accept. Out of the total of 300 cents, what do you think the smallest offer was, that the player B that you were matched to said that s/he would accept?

This means that any offer equal to this, or larger, would be accepted by player B. Any offer smaller than this would be rejected by player B.

I think that the smallest amount that player B was willing to accept was (in cents):

Q2 How many tables do you think that you solved correctly in part 1? (The maximum was 15)

Q3 How many tables do you think that everyone who participate in this experiment on average solved correctly? (The maximum was 15 . Please round up your answer to the closest integer.)

Q4 On a scale of 1 to 10 , do you feel that you deserved to be player A?

Q5 In your opinion, what would a 'fair' distribution of the 300 cents be from the perspective of a third party who is not part of the pair?

Q6 How do you see yourself: Are you generally a person who is fully prepared to take risks or do you try to avoid taking risks?

Q7 Was there any part of the experiment that confused you, or do you have any other comments?

\section{Player B:}

The game has now been conducted and you will learn the outcome after you have answered the questions on this screen.

Q1 What suggestion do you think that your counterpart player A made?

Q2 How many tables do you think that you solved correctly in part 1? (The maximum was 15)

Q3 How many tables do you think that everyone who participate in this experiment on average solved correctly? (The maximum was 15 . Please round up your answer to the closest integer.)

Q4 On a scale of 1 to 10, do you feel that the other person in your pair deserved to be player A?

Q5 In your opinion, what would a 'fair' distribution of the 300 cents be from the perspective of a third party who is not part of the pair? 
Q6 How do you see yourself: Are you generally a person who is fully prepared to take risks or do you try to avoid taking risks?

Q7 Was there any part of the experiment that confused you, or do you have any other comments?

[Feedback about earnings is given]

Thank you for your participation!

Your completion code is:

Please enter this code into the space provided by MTurk.

We will calculate and pay bonuses within the next few days. 